Summer 8-24-2019

\title{
Exploring the Role of Occupational Therapy in Primary Care
}

Tina Rosselli

University of St. Augustine for Health Sciences

DOI: https://doi.org/10.46409/sr.DVWS5843

Follow this and additional works at: https://soar.usa.edu/capstones

Part of the Community Health and Preventive Medicine Commons, Occupational Therapy Commons, and the Patient Safety Commons

\section{Recommended Citation}

Rosselli, T. (2019). Exploring the Role of Occupational Therapy in Primary Care. [Doctoral project, University of St Augustine for Health Sciences]. SOAR @ USA: Student Capstone Projects Collection. https://doi.org/10.46409/sr.DVWS5843

This Capstone is brought to you for free and open access by the Student Research at SOAR @ USA. It has been accepted for inclusion in Student Capstone Projects by an authorized administrator of SOAR @ USA. For more information, please contact soar@usa.edu, erobinson@usa.edu. 


\title{
EXPLORING THE ROLE OF OCCUPATIONAL THERAPY IN PRIMARY CARE by
}

Tina M. Rosselli

\author{
A Capstone Project Presented in Fulfillment \\ of the Requirement for the Degree of \\ DOCTOR OF OCCUPATIONAL THERAPY
}

University of Saint Augustine for Health Sciences

August 2019 
EXPLORING THE ROLE OF OCCUPATIONAL THERAPY IN PRIMARY CARE

by

Tina M. Rosselli

has been approved

August 2019

APPROVED:

ERIN SCHWIER, EdD, OTR/L, Program Director

SUSAN MACDERMOTT, OTD, OTR/L, Doctoral Coordinator

ACCEPTED AND SIGNED:

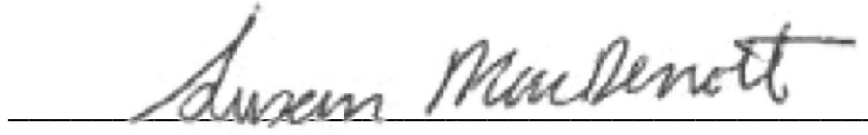

Susan MacDermott, OTD, OTR/L, Doctoral Coordinator

Digitally signed by eschwier@usa.edu

eschwier@usa.edu $\begin{aligned} & \text { Digitally signed by } \begin{array}{l}\text { DN: cr=eschwier@usa.edu } \\ \text { Date: 2019.08.23 07:39:43-07'00 }\end{array} \\ & \text { a }\end{aligned}$

Erin Schwier, OTD, OTR/L, Program Director 
Table of Contents

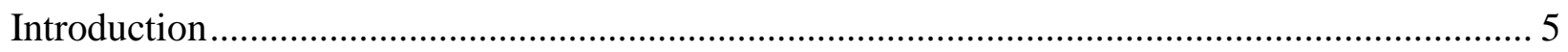

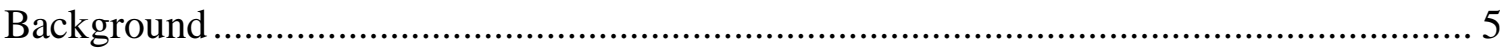

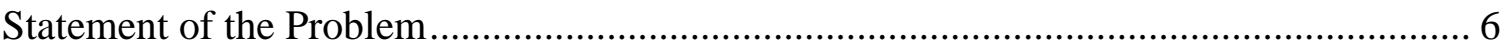

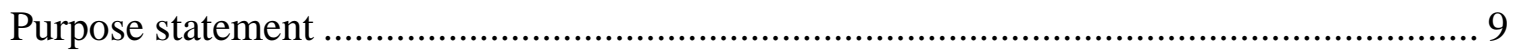

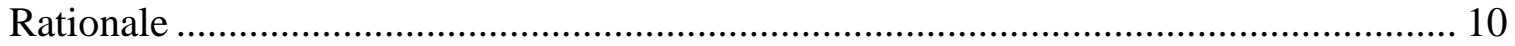

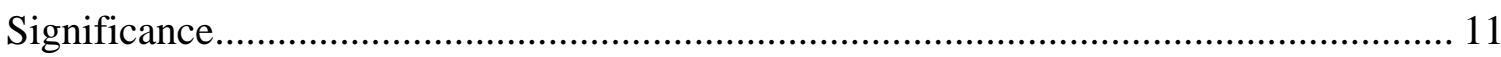

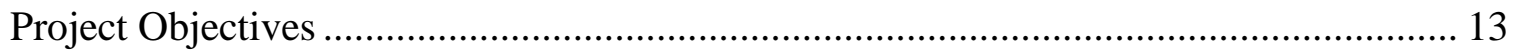

Definition of Terms...................................................................................... 14

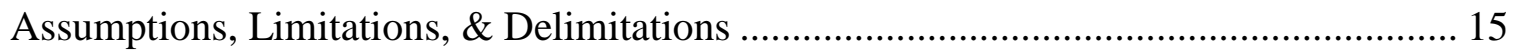

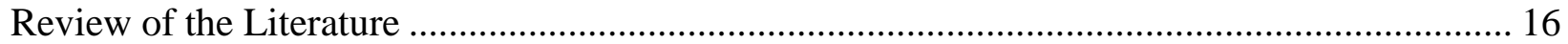

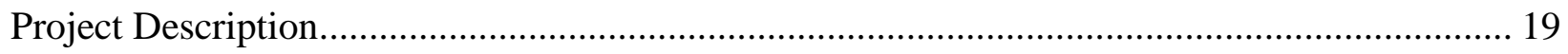

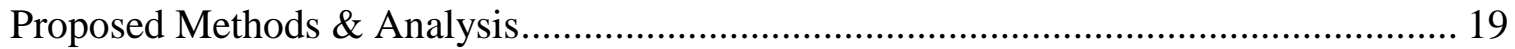

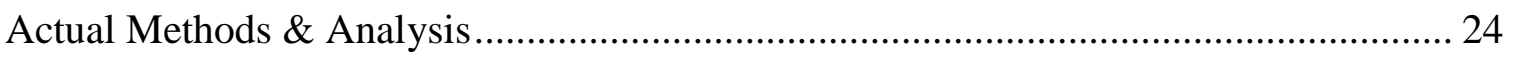

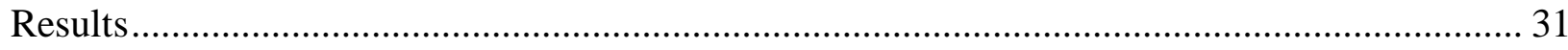

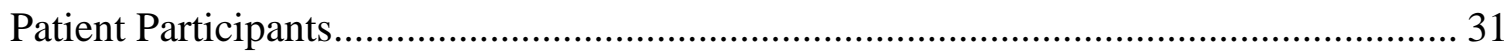

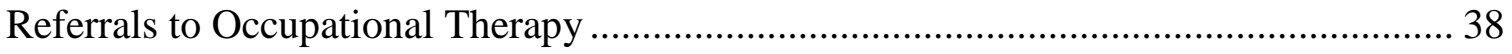

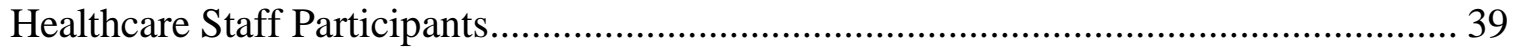

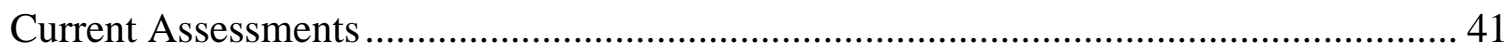

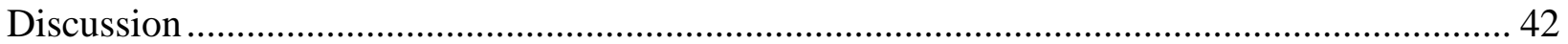

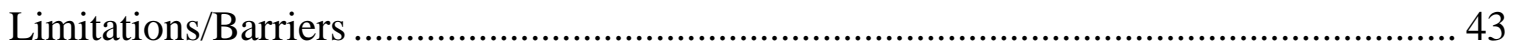

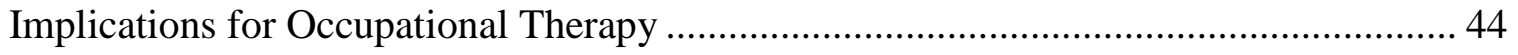

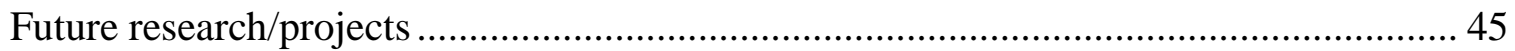




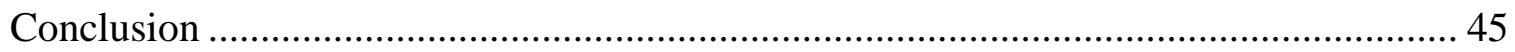

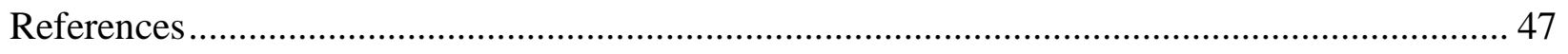

Appendix A: Occupational Participation Assessment for Primary Care ….............................. 52

Appendix B: Occupational Participation Assessment for Primary Care (Spanish) ................... 54

Appendix C: Healthcare Staff Presentation ................................................................... 56

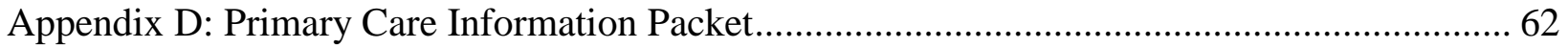

Appendix E: Post-Presentation Healthcare Staff Survey ................................................ 71

Appendix F: Current Assessment Protocol Documents..................................................... 73 


\section{Introduction}

\section{Background}

Primary care is often the first point of contact for a patient to enter the health-care system. This is where a patient is seen to discuss symptoms, get a diagnosis or physical exam, or get referred out to specialists for health issues that require a more specific expertise. Primary care is defined as a setting "that provides integrated, accessible health care services by clinicians who are accountable for addressing a large majority of personal health care needs, developing a sustained partnership with patients, and practicing in the context of family and community" (cms.gov, n.d.). The health care system in the United States is ever-changing. Amongst the many changes in the healthcare world, one is moving towards value-based healthcare instead of feefor-service. Value-based care means focusing on the use of outcome measures to determine if a service is valuable for the patient and paying for valuable outcomes rather than quantity (fee-forservice). This is known as the Alternative Payment Model (APM), and Medicare has recently implemented this into its payment delivery system. "The Centers for Medicare and Medicaid Services (CMS) in particular supports many efforts to advance quality and innovation in primary care through APMs to incentivize providers to engage in high-quality care by linking payment to processes and outcomes" (Halle, Mroz, Fogelberg, \& Leland, 2018, p. 2). These processes and outcomes can include prevention screening, healthcare coordination, hospital readmissions, and functional assessments.

Occupational therapy (OT) is an allied health profession that focuses on helping people to participate in activities that are meaningful and purposeful (called occupations) to promote longevity and prevent the onset of or the affects from complex chronic conditions. Primary care 
is an emerging practice setting for occupational therapy. Occupational therapists, being professionals in such a wide scope including prevention of health decline, rehabilitation, and physical and mental health, carry a holistic lens that not many healthcare providers utilize. Occupational therapists have a unique skillset to be able to analyze all the personal and environmental factors that impede a person's ability to perform a valued activity. Traditionally, in the medical field, occupational therapists see patients during or after a hospitalization, however having a background in all these areas, OT can have a significantly important role intervening sooner within a primary care setting (Muir, Farmer, \& Prestwich, 2013). Within the definition of primary care, "addressing a large majority of personal health care needs" runs parallel to the areas of occupational therapy, including activities of daily living (ADLs), instrumental activities of daily living (IADLs), play and leisure, work, education, rest and sleep, and social participation (American Occupational Therapy Association [AOTA], 2014). OT can complement an interprofessional team within a primary care setting by dealing with issues that affect occupational participation, function and quality of life.

\section{Statement of the Problem}

According to the Center for Disease Control (CDC), approximately one-fourth of people diagnosed with a chronic condition experience significant limitations in daily activities (2018). "More than 25\% of all Americans and 2 out of 3 older Americans have multiple chronic conditions" (Holstein, 2018, p. 496). Some chronic diseases and illnesses that are seen often in primary care include heart disease, hypertension, obesity, arthritic and musculoskeletal problems, diabetes, chronic obstructive pulmonary disease (COPD), and depression (Brown, 2018; Gallagher, Lyons, Houston \& Cummins, 2016). Having one or more chronic conditions has its 
effects on one's function, however, now add in the typical aging body processes like decrease in vision, strength, coordination, reflexes, and sensation, and imagine the impact on their daily lives.

There are a growing number of baby-boomers wanting to stay home as long as they can before needing assistance from an outside resource. This is known as "aging in place." In order for an elderly person with a chronic condition to be safe at home by themselves for any given time, they need to be able to ambulate and complete their daily activities safely. "In the geriatric population, the initial sign of a medical problem may be a decline or change in function rather than a clinical abnormality" (Tran \& Leonard, 2017, p. 400). For example, neuropathy caused by diabetes can affect one's ability to feel for unsafe temperatures. COPD can be dangerous for someone needing to shower, get ready for the day, and finish their house chores. Someone with severe arthritis in their joints may find it too painful to care for themselves, so they avoid bathing or making meals.

According to a study that measured the amount of time primary care physicians/providers (PCPs) spend on preventative services with patients, it was concluded that PCPs did not have enough time to properly assess a patient's safety and quality of life at home or in the community (Yarnall, Pollak, Ostbye, Krause, \& Michener, 2003). "PCPs experience time pressure when they encounter either many patients with one urgent medical issue, or one patient with many medical issues" (Sandelowski et al., 2016, p. 59). Due to time constraints, they are usually more focused on addressing the patient's immediate concerns and symptoms. Dr. Jeffrey Walden, a primary care physician in a community-based clinic reports two primary causes of physician burnout are "decreased time spent with the patient," and "the inability to achieve the highest standard of care 
for all patients..." (2016). Primary care visits are usually allotted less than 20 minutes, and when patients are coming in with multiple conditions, a physician is forced to prioritize what he or she can focus on (Linzer et al., 2015). When any health or safety concerns are unaddressed, patient satisfaction decreases, there are more emergency room visits, and it becomes more difficult for a patient to adhere to treatment plans (Linzer et al., 2015). Therefore if a physician notices any concerns in regard to health or safety, and if time is a factor, they may refer the patient out to other services or facilities. When a patient is sent away for services, it often leads to fragmentation of care where they may experience a "lack of access to services, loss of continuity of care, and the failure of health services to meet their needs" (Montenegro et al., 2011).

Very few occupational therapists practice in primary care due to barriers including uncertainty concerning the role of the profession as well as misunderstanding regarding how reimbursement works for OT in primary care (Halle et al., 2018). When the role of a profession in any setting is unclear, it can be difficult for others to be receptive of allowing this new role to join their team. In this case, if doctors, nurse practitioners, physician assistants, nurses, and all other medical and administrative staff understood how collaborating with occupational therapy can help them and their patients, they may be more accepting of having one on their interprofessional team. Many health workers believe they already work in such a team as they all are using their skills to work toward a common goal, however "collaboration occurs when two or more individuals from different backgrounds with complementary skills interact to create a shared understanding" (World Health Organization [WHO], 2010). Occupational therapy practitioners can make a unique contribution in primary care by recognizing and addressing how habits and routines impact the management of chronic conditions and how participating in one's meaningful activities improves their quality of life (American Occupational Therapy Association 
[AOTA], 2018). One of the numerous ways a primary care physician and an OT can complement one another is described below.

As Michelle Farmer, OTD, OTR/L, described the patient who was 12 weeks pregnant, extremely disorganized, anxious, depressed, and hallucinating, Brian Prestwich, MD, wanted to offer his perspective. "So, what do I see as a physician?" asked Prestwich, the then medical director at a Federally Qualified Health Center (FQHC) affiliated with the University of Southern California (USC) in Los Angeles. "The patient is functioning well enough, and her low-grade hallucinations are not an immediate threat to her or others. So, medically, I understand how to take care of her. I know how to treat her depression and her hallucinations. But I have no idea how to get the chaotic life around her to calm down so she can execute a treatment plan. That's where I turn to (Farmer)" (Waite, 2014, p. 8).

\section{Purpose statement}

There is an absence of assessment of occupational participation in primary health care. This absence can lead to an increase in hospital admissions, increased health care costs, and a continued decline in the health of adults who suffer from acute or chronic conditions. The issues of short visits with patients and a new need to achieve value-based results in order for physicians to get reimbursed for their time are reasons why occupational therapy not only fits so well but is imperative to primary care success. Due to time constraints, it is uncommon for adults seen in primary care settings to get routine measurements of their functional status and although health care systems are aware of this deficit, they have been slow to incorporate this type of assessment into practice (Spar, Nicosia, Steinman, \& Brown, 2017). This capstone project aims to explore the role of occupational therapy for adults within a primary care setting by completing functional 
assessment interviews with patients, reviewing patient charts, and surveying providers and other healthcare staff. This project intends to educate physicians and medical staff about the distinct knowledge and skills held by occupational therapy in hopes of offering a greater understanding of the scope of practice and benefit of the addition of occupational therapy to the primary health care team.

\section{Rationale}

Theories and models are imperative to healthcare research, promotion, and practice. The health promotion model's main tenets include community participation, empowerment, social justice, greater autonomy for the community, importance of active and meaningful lifestyles, and respect for cultural diversity (Thibeault \& Hebert, 1997). These are all lifestyle factors that can influence or prevent health behaviors. Under this model, healthcare workers are meant to assess a person's lifestyle factors and look for ways to prevent health decline. Occupational therapists use this model to motivate people to become better self-managers and empower them to make healthy lifestyle choices. Using this model in the primary care setting, a health care team would be able to work collaboratively with occupational therapy to assist the patients in obtaining optimal health and wellness.

Federally Qualified Health Centers (FQHCs) are community-based primary health care centers who are funded by the Health Resources and Services Administration (HRSA) to provide low- or no-cost healthcare to underserved communities. FQHCs can provide healthcare to patients covered by Medicaid, Medicare, and private payers. More than 27 million patients received care at a federal health center in 2017 (Health Resources and Services Administration [HRSA], 2018). Occupational therapists can contribute to health equity, a basic principle of 
ethical health care, by offering their unique and necessary services to underserved communities. With the recent advancements made with Medicare moving towards more value-based patient care versus the typical fee-for-service, there is no better time to advocate for occupational therapy to be a part of an interdisciplinary team within primary health care at the FQHC level.

Many federally qualified health centers follow a Patient-Centered Medical Home model, which is a philosophy of primary care that is team-based, coordinated, easily accessible to the patient, is focused on quality of care, and of course, is patient-centered. According to National Committee for Quality Assurance (NCQA), PCMH includes the following 5 functions: comprehensive care, patient-centered, coordinated care, accessible services, and quality and safety (2014). The Accreditation Council for Occupational Therapy Education (ACOTE), has educational standards that can be matched with the standards for patient-centered medical home. These matched standards between ACOTE and PCMH include, "Enhance access to and continuity of care," "Identify and manage patient populations," "Plan and manage care," "Provide self-care support and community resources," "Track and coordinate care," and "Measure and improve performance" (Moyers \& Metzler, 2014). With overlapping values and goals, OT practitioners are perfect candidates to create and assume roles within a PCMH.

\section{Significance}

Including occupational therapy in the care of adults within the primary care setting, “especially when a new diagnosis is made or when the full impact of a problem is not easily understood, can bring the profession's expertise in participation in daily life, self-management, and optimum development right to the patient, right when it is needed" (Lamb \& Metzler, 2014, p. 11). Studies show that occupation-focused and occupation-based therapy in adults, where 
activities are practiced as the focus of intervention, and cognitive, behavioral and environmental strategies are used, can significantly improve one's ability to participate in daily activities (Nielsen, T., Peterson, \& Nielsen, C., 2016). As mentioned, a person's ability to engage in meaningful and purposeful activities is what drives their health. Physical and mental health disorders can be addressed at the primary care level by physicians as well as occupational therapists. Evidence suggests that occupational therapy intervention combined with primary care physician treatments, like medications, for mental health illness is associated with improved patient occupational performance (Gallagher et al., 2016). Occupational therapist practitioners can be a part of the value-based healthcare delivery system where they use their unique expertise to help patients live safer, more fulfilling and healthier lives.

The significance of this capstone project is directly related to the crisis of high health care costs and the need to have value-based outcomes as a strong basis for hiring practitioners and making treatment decisions. An independent study by health policy researchers published in Medical Care Research and Review found that "occupational therapy is the only spending category where additional spending has a statistically significant association with lower readmission rates" for the three health conditions studied: heart failure, pneumonia, and acute myocardial infarction (Rogers, Bai, Lavin, \& Anderson, 2016). OT's role in decreasing hospital readmissions can be addressed in the primary care setting where they can "recognize deficits in self-care and function that might lead to a readmission, such as problems related to meal preparation, access to medications, bathroom access, toileting, and the need for nursing aides or family education" (Rogers et al., 2016). The value-based outcomes are based on the "triple aim" goals of healthcare which are improving the quality of care, improving population health, and reducing the cost for care (Lamb \& Metzler, 2014). When given the opportunity, occupational 
therapists can partner with primary care health professionals to improve the health outcomes of their most at-risk patients and in turn, play a significant role in reaching the triple aim goals.

When a person can no longer participate in their meaningful occupations due to safety or other concerns, their health will decline as well. As older adults age, most want to remain in their own homes for as long as they can (Dickson \& Toto, 2018). Exploring the role of occupational therapy in primary care will not only allow for opportunity to inform the community about the profession, but it will hopefully convince other health professionals that there is a need to collaborate with OT to better serve their patients.

\section{Project Objectives}

1. To assess the occupational limitations and needs of adult patients in primary care settings through semi-structured interview and chart review

2. To determine if there are specific underlying performance skills and/or client factors lacking in current assessment protocol

3. To determine if there is a common area of concern with performance of ADL/IADLs

4. To identify current strategies used in the primary care setting to link patients to community services

5. To measure the understanding of healthcare staff of the role of the occupational therapy profession in primary care

6. To measure the receptiveness of healthcare staff to incorporating occupational therapy into their interdisciplinary teams 


\section{Definition of Terms}

Primary care. A setting that provides integrated, accessible health care services by clinicians who are accountable for addressing a large majority of personal health care needs, developing a sustained partnership with patients, and practicing in the context of family and community (cms.gov, nd).

Patient-centered medical home (PCMH). A Patient Centered Medical Home (PCMH) is an approach to primary care that puts the patient at the center of his/her care while receiving a "full range of comprehensive services provided by a team of health professionals including social worker, nurse and pharmacist, in addition to the primary care provider" (Healthserviceinc.org, 2018). In a PCMH, care teams collaborate to create the best course of action for patients with a focus on prevention and chronic disease management.

Federally qualified health center (FQHC). In order for a health center to be considered a Federally Qualified Health Center (FQHC) they must:

I. "Qualify for funding under section 330 of the Public Health Service Act

II. Qualify for enhanced reimbursement form Medicare and Medicaid

III. Serve an underserved area or population

IV. Offer a sliding fee scale

V. Provide comprehensive services (either on-site or by an arrangement with another provider) including:

a. Preventative health services

b. Dental services

c. Mental health and substance abuse services

d. Transportation services necessary for adequate patient care

e. Hospital and specialty care 
VI. Have an ongoing quality assurance program

VII. Have a governing board of directors" (FQHC.org, n.d.)

Fragmentation of care. Fragmented care involves multiple clinicians who are not effectively communicating information about a patient, leading to less than optimal healthcare (Improvingchroniccare.org, n.d.). "Furthermore, in fragmented systems, users experience lack of access to services, loss of continuity of care, and the failure of health services to meet their needs" (Montenegro et al., 2011, p. 5).

Functional Status. "Functional status can be seen as a measure of overall health impact in the context of an individual's environment and social support network" (Tran \& Leonard, 2017, p. 400).

\section{Assumptions, Limitations, \& Delimitations}

Based on the literature review, it can be assumed there is a deficiency of representation of occupational participation in the primary care setting, there is a deficit in adherence to physician treatment plans into patients' roles and routines, and there is a lack of knowledge and awareness amongst healthcare providers about the scope of occupational therapy practice.

There are several limitations to this project. The amount of time available to gather data and present findings is based on the university's academic calendar. In this allotted time, the sample size will be reduced to only patients who are uninsured, self-pay, or have a health insurance plan that the clinic is contracted with. The student may have limited access to confidential information based on viewable data in the electronic health system. Other limitations include the socio-economic status of patients, and types of diseases, disorders, or conditions that come into the office. This project is also limited to the type of assessment performed as the student cannot perform assessments using skilled occupational therapy without supervision. Delimiting factors related to this capstone project include the choice of objectives, 
theoretical perspectives, geographic region, and organizations involved. This project seeks to find the need to further primary healthcare with occupational therapy through use of the health promotion model where community, culture, and social justice are healthcare bridges to service delivery.

\section{Review of the Literature}

To further understand the purpose of this capstone project, we must examine the roles of occupational therapy in primary care around the world and the gaps in current approaches primary care providers are taking to assess their patients.

Based upon current literature occupational therapy has already made an enormous contribution to primary care all over the world. In Ireland, where occupational therapists are already an integral part of the primary care system, OTs are in the process of expanding their role in primary care to include the assessment of mental health aside from considering one's physical health. Healthcare models that allow for direct pathways to psychological or lifestyle treatments in the primary care by self-referral or referral by a primary care physician are gaining support in Ireland (Gallagher, Lyons, Houston, \& Cummins, 2016). In Canada, researchers and the national occupational therapy organizations have proven that inclusion of occupational therapy in primary care is not only beneficial to the healthcare system, but also its "diversity of service is reflective of the primary care setting, which by nature is responsive to local client and community needs" (Donnelly, Leclair, Wener, Hand, \& Letts, 2016, p. 138). Other countries that currently have OT integrated into primary care are Australia, New Zealand, and South Africa (Dahl-Popolizio, Doyle, \& Wade, 2018). 
Research describes several examples of the roles that occupational therapists currently have in the primary care setting as:

- Support to the physician and care team by means of prevention of disease or disability

- Improving quality of life when a disease or disability is already present

- Promoting lifestyle redesign and health management

- Using a person's own habits, routines, and roles to aide in regimen compliance

- Assessing a patient holistically to identify what factors are affecting their function

- Providing interventions that can be performed at home

- Prescribing necessary adaptive equipment

- Wheelchair fitting

- Aiding in community integration

- Coordinating palliative or hospice care

- Mental health support

- Diabetes program management

- Splinting

- Driver screening

- Educating on self-management techniques (Dahl-Popolizio et al., 2018; Donnelly, O’Neill, Bauer, \& Letts, 2017; Muir, 2012; Pyatak, Carandang, \& Davis, 2015).

One of the earliest published studies by Eileen E. Bumphrey in 1987 describes the role of occupational therapy in a primary care team, which was called a Community Care Group, as one who ensures that a patient is functionally able to participate in their daily activities safely. 
According to CMS services, primary care physicians provide an annual wellness visit (AWV) which is a "visit to develop or update a personalized prevention plan and perform a health risk assessment" (2018). Some information required by Medicare to collect at an AWV includes a patient's demographics, a self-assessment of their health status, psychosocial and behavioral risks, and their ADL and IADL status (CMS, 2018). Other areas meant to be covered at an AWV include an update on the patient's medical and family history, current measurements (i.e. weight, height, BMI), an assessment of their current cognitive status, and providing referrals to outside health professionals to cover fall prevention, nutrition, physical activity, tobacco-use cessation, cancer screenings, and weight loss (CMS, 2018). While visits to a primary care physician run approximately 20-minutes long, studies show how it is just not feasible to obtain all the required information in one sitting (Linzer et al., 2015; Ostbye et al., 2005; Yarnall et al., 2003). Research suggests that the most common barriers to delivery of such comprehensive care are "lack of time during an office visit, inadequate insurance reimbursement, patient refusal to discuss or comply with recommendations, and lack of physician expertise in counseling techniques" (Yarnall et al., 2003, p. 635).

In summary, there are many roles occupational therapists have in primary care facilities around the world and how current approaches to primary care visits do not provide the physician with a complete picture of the patient's health. The gaps in the literature provide us with limited information regarding the current primary care evaluation and assessment protocol and the failure to include occupational participation. This capstone project aims to address these concerns by exploring the role of occupational therapy in community health centers by means of identifying occupational participation deficits. 


\section{Project Description}

\section{Proposed Methods \& Analysis}

Borrego Health is a Federally Qualified Health Center in California with over 20 locations serving San Bernardino, Riverside, and San Diego counties. This capstone experience will be completed at various Borrego sites to include Centro Medico clinic in El Cajon, Centro Medico clinic in Escondido, and Desert Hot Springs Health \& Wellness Center in Palm Springs during the Summer of 2019. The student will be under the supervision of a primary care physician who spends time at both the El Cajon and Escondido locations. If the desired number of eligible participants is not met at these two sites, the project will be continued at the Palm Springs location.

This project will use a screening tool developed for adults aged 18 and older being seen in the primary care unit for either acute or chronic conditions. Chart reviews will be conducted the day prior to patients' visits, or same day, to ensure appropriateness of sample. Participants will be recruited via convenience sampling where the student researcher will have a list of patients with whom are scheduled to see the supervising physician. Patients who meet the inclusion criteria will be asked to participate in a semi-structured interview and sign a statement of consent to use information gathered for intended project purposes only. Patients will be interviewed either prior to their scheduled appointment time with their physician or after their appointment has concluded. The location of interviews will depend on whether the patient was already processed and escorted into an exam room, or whether they arrived early enough to conduct the interview in a private designated area in the unit. Patient interviews will take place 
for approximately 12 weeks, or until a sample size of 100 patients $(n=100)$ have completed the survey/interview.

The screening tool developed for the purposes of this capstone project, called the Occupational Participation Assessment for Primary Care (OPAPC) is shown in Appendix A. "Occupational participation incorporates the occupations in which clients engage, occupational demands, routines, skills, and occupational performance” (Pizzi \& Richards, 2017). A person's quality of life is influenced by these factors which makes them important areas to assess when considering one's overall health and well-being. The questions begin with a basic occupational profile including the patient's type of home (apartment, house, mobile, etc.), how many steps there are to enter the home, whether they have a walk-in shower or a bathtub shower, who they live with and what durable medical equipment they own. Next, questions ask how many primary care visits and emergency room visits they have had in a given time. This may be compared to the data shown in the electronic health record for confirmation. The following section asks how much assistance the patient believes they require for ADLs and IADLs. The next questions ask about the patient's recent balance and fall history. The interview ends with a few mental health questions focusing on whether mental health issues have affected his/her occupational engagement.

The purpose of using a cross-sectional survey design is to generalize information gathered from a sample to a greater population by means of categorizing responses into quantifiable data. Performing this project at these few health clinics can potentially provide enough evidence to be referenced to many other health clinics. In order for information from this capstone project to be available to share with organizations outside of Borrego health, the student 
researcher will submit a request for approval by the Institutional Review Board of the University of St. Augustine for Health Sciences.

The OPAPC was developed as self-report instead of a clinical assessment because the researcher is a candidate for the Doctor of Occupational Therapy degree, and therefore is unlicensed at this time. This tool was influenced by the Lawton IADL and Katz ADL standardized questionnaires. A tool that incorporated all the areas in the OPAPC was not found in the literature, and therefore the first draft of this assessment was developed. This OPAPC is intended to be altered and adapted as necessary during the length of the project. Intake forms, questionnaires, surveys, and interviews already performed by the healthcare staff will be reviewed to distinguish any overlapping questions. If learned that the primary care staff include similar questions in their intake documents, those similar questions may be reformed or removed from the OPAPC, while if a topic related to a patient's occupational performance or participation is found to be missing on the OPAPC, it can be added at any time. At the term of the project, a final draft of the OPAPC will be shown to clinic healthcare staff along with other standardized assessments (like the Katz) that can show how much more a licensed OT can assess (i.e. gait, strength, proprioception, cranial nerves, mental health). Individual completed OPAPC forms will be uploaded to each patient's chart with the original copy remaining with the student researcher for future data analysis. A unique number will be placed at the top of each assessment form which will be logged to match the patient's name or medical record number in case the student researcher needs to review the patient's chart for information verification or if additional information is required. 
A field-test of the survey was completed with the first draft of the OPAPC having been shown to five people with no health care background. This test was important to validate the content of the survey and method of interview. The interviews lasted between 10 and 15 minutes, depending if the person required a translator. People who required translation required approximately 15 minutes to complete the interview. It was important to include translation examples in the field-test of the interview as it is anticipated there will be a large percentage of Spanish- and Arabic-speaking patients at the El Cajon clinic based on city statistics (Data USA, 2015). The site will provide a translator or English-speaking family will be utilized if needed. After the initial field-test of the interview, the dialogue between the test participants and student became much more natural, requiring less time to transition between sections. Edits made include changing, "Number of primary care visits per month," to, "Number of primary care visits per year," as all responses were, "less than once per month." Added to the interview questionnaire assessment was, "If yes, is your pain being managed?" This was added after the question, "Do any of the above activities cause pain or aggravate existing pain?" Adding this was important because having pain is one issue, however whether it is being managed informs the student researcher if pain is a factor in the patient's occupational engagement.

Additional areas of observation will include how healthcare staff connect patients to outside community services or healthcare specialists that would be beneficial to their health and well-being. This can include, but is not limited to, referrals to community and government programs, referrals to specialists, and any physical materials handed to the patient like flyers or information packets. 
Once the patient surveys have been analyzed, the student researcher will present to the healthcare staff of Borrego Health during a luncheon in-service. This presentation will include findings of the project as well as a clear description about the value and potential role that occupational therapy can have in the primary care setting. After the presentation, healthcare staff will be asked to complete a short survey which will measure both their understanding of the role OT can have in primary care and how receptive they are to incorporating OT into their interdisciplinary care teams. This survey was influenced by a study published in The Open Journal of Occupational Therapy called “Occupational Therapy in Primary Care: Determining Receptiveness of Occupational Therapists and Primary Care Providers" (2017), which determined that once educated about the role that OT has in primary care, primary care providers supported the inclusion of OT in this setting.

Data analysis will be completed at two different occasions. First, once all participant interviews have been finalized, and second, once all staff surveys have been completed. Patient survey questionnaires filled out during the interviews will have a unique identification number, as mentioned above. Analysis of the patient questionnaires as well as the staff surveys will begin with recording information about the number of participants who completed the survey. Next, a descriptive analysis of both survey findings will be completed using Tables 1 and 2 below which quantify the responses from each question. Data extracted from patient surveys will be analyzed and organized into Microsoft Excel to distinguish the most prevalent occupational needs and any patterns suggesting possible factors not being addressed in the facility's current primary care assessment practice. Data collected in the healthcare staff post-presentation surveys will also be analyzed to recognize any themes involving the participant's job title, understanding of the role occupational therapy has in primary care, and whether there is an overall receptiveness to 
including OT in this setting. Other areas of observation, such as what the current assessment protocol in primary care is, how patients are connected to community services, and referrals will be documented as that information becomes understood.

\section{Actual Methods \& Analysis}

This project was completed at two Borrego sites to include Centro Medico clinic in El Cajon and Centro Medico clinic in Escondido during the Summer of 2019. The student was under the supervision of a primary care physician who spent time at both the El Cajon and Escondido locations. One-month into this capstone project, the primary care supervisor's schedule changed, and he remained at the Escondido location for the remainder of the time. The desired number of eligible participants was met $(n=150)$, therefore the student did not need to go to the additional Palm Springs clinic location.

Upon completion of the Doctor of Occupational Therapy program in August 2019, the student will apply to do a retrospective study in which will utilize all data gathered from this project. In order for information from this project to be available to share with organizations outside of Borrego health as a research study, the student will request for this approval by the Institutional Review Board of the University of St. Augustine for Health Sciences. The goal with this would be to eventually be able to generalize information gathered from this sample to a greater population by means of categorizing responses into quantifiable data. Completing this project at these few health clinics can potentially provide enough evidence to be referenced to many other health clinics nationally.

This capstone project used a screening tool developed for adults aged 18 and older who were seen in the primary care unit for either acute or chronic conditions. The screening tool 
developed for the purposes of this project, called the Occupational Participation Assessment for Primary Care (OPAPC) is shown in Appendix A. Chart reviews were conducted the same day of patients' visits to ensure appropriateness of the sample. Participants were recruited via convenience sampling where the student had a list of patients with whom were scheduled to see the supervising physician as well as other primary care providers working that day. Patients who met the inclusion criteria were asked to participate in a semi-structured interview and provide a verbal consent to use information gathered for intended capstone project purposes. Patients were interviewed in their exam room either prior to their scheduled appointment time with their physician or after their appointment was concluded. It was decided to use verbal consent versus the planned written consent to keep all data unidentifiable.

If patients were non-verbal or severely cognitively impaired, the interview was completed by their caregiver and mental health questions were documented as "NA" for "Not Applicable." The last question of the interview was a safety check question which was, "If an emergency was to happen in your home, such as your kitchen catching on fire, and you were alone, what is the first thing you would do?" The only two responses marked as appropriate were anything along the lines of, "Leave the house," or "Call 911.” All other responses to include, "I don't know," or "Wait for my spouse to get home," were marked as inappropriate.

A unique number was placed at the top of each completed OPAPC interview form in order to organize them and be able to log responses into Microsoft Excel for data analysis. The interview forms carried only unidentifiable information. Patient interviews took place for approximately 10 weeks, until the goal of a sample size of 150 participants $(n=150)$ was reached, with 50 participants coming from each age group. The 150 participants consisted of 50 young 
adults (18-44 years old), 50 middle-aged adults (45-64 years old), and 50 older adults (65+ years old). The goal sample size increased from 100 to 150 because there was ample patient availability and the student decided to have an equal number of participants from each agegroup. Having equal numbers from each age-group would allow data to be comparable as each age-group can have varying functional status' and occupational participation.

The Occupational Participation Assessment for Primary Care (OPAPC) was used as a tool to guide interviews with patients. The OPAPC was developed as self-report instead of a clinical assessment because at the time this capstone project was being completed, the student was a candidate for the Doctor of Occupational Therapy degree, and therefore was not yet licensed. In the primary care clinic setting, it is recommended to have a licensed occupational therapist confirm all that the patient self-reports in regard to their occupational engagement. The OPAPC was translated into Spanish so the student would not always require a translator as the student was able to read, speak, and understand Spanish (Appendix B). The OPAPC was not translated into Arabic, as the student cannot read, speak, or understand Arabic, however a translator was always available if needed.

Another field-test of the OPAPC was completed prior to initiating actual data collection on site, with interviews being completed for one-week to approximately 10 adult patients of varying ages. This test was imperative to validate the content and method of interview delivery. Questions that were added after the first week of practice interviews included ones regarding shortness of breath, sensation deficits, strength deficits, and whether any of these factors affected the participants' occupational engagement. These practice interviews were not counted in the 150 collected interview forms. Also completed during the first week of this capstone project, 
intake forms, questionnaires, surveys, and interviews already performed by the healthcare staff were obtained and reviewed to distinguish any overlapping questions.

Additional areas of observation include how healthcare staff connect patients to outside services. This involved viewing the process of referrals to specialists and any physical educational materials handed to the patient.

Data analysis was completed at two different occasions. First, when all participant interviews were finalized, and second, when all staff surveys were completed. Patient survey questionnaires filled out during the interviews each had a unique identification number, as mentioned above. Analysis of the patient questionnaires as well as the staff surveys began with recording information about the number of participants who completed the survey. Next, a descriptive analysis of both survey findings was completed using Tables 1 and 2 below which quantify the responses from each question by using codes for each category. Data extracted from patient surveys was analyzed and organized into Microsoft Excel. Table 2 shows how responses from participants 1 through 25 were organized. This data was used to distinguish the most prevalent occupational needs and any patterns suggesting factors affecting occupational engagement. Data collected in the healthcare staff post-presentation surveys was analyzed to recognize any themes involving the participant's job title, understanding of the role occupational therapy has in primary care, and whether there was an overall receptiveness to including occupational therapy in this setting. Other areas of observation, such as what the current assessment protocol in primary care is, and how patients are connected to community services and referrals were noted as that information became understood. 
Table 1.

Occupational Participation Assessment for Primary Care (OPAPC) Data Analysis Key

\begin{tabular}{|c|c|c|c|c|c|}
\hline Variable & Response & Code & Variable & Response & Code \\
\hline \multirow[t]{3}{*}{ Age (Adult years) } & Young (18-44) & 1 & Toilet hygiene & Independent & 1 \\
\hline & Middle-Aged (45-64) & 2 & & Assistance/Supervision & 2 \\
\hline & Older (65 and above) & 3 & & Dependent & 3 \\
\hline \multirow[t]{2}{*}{$\mathrm{M} / \mathrm{F}$} & Male & 1 & Personal device care & Independent & 1 \\
\hline & Female & 2 & & Assistance/Supervision & 2 \\
\hline \multirow[t]{4}{*}{ Home type } & House & 1 & & Dependent & 3 \\
\hline & Condo/Apartment & 2 & Making a meal & Independent & 1 \\
\hline & Mobile home & 3 & & Assistance/Supervision & 2 \\
\hline & Homeless/Other & 4 & & Dependent & 3 \\
\hline \multirow[t]{2}{*}{ Bathroom } & Bathtub & 1 & Feeding & Independent & 1 \\
\hline & Walk-in Shower & 2 & & Assistance/Supervision & 2 \\
\hline \multirow[t]{4}{*}{ Lives with } & Alone & 1 & & Dependent & 3 \\
\hline & Spouse/Partner only & 2 & Ability to use a phone & Independent & 1 \\
\hline & Family/Friend(s) & 3 & & Assistance/Supervision & 2 \\
\hline & Caregiver & 4 & & Dependent & 3 \\
\hline \multirow[t]{5}{*}{ Ambulation DME } & None & 1 & Driving/Community transport & Independent & 1 \\
\hline & \multirow{4}{*}{$\begin{array}{l}\text { Powerchair/Wheelchair } \\
\text { Front-Wheeled Walker } \\
\text { 4-Wheeled Walker } \\
\text { Cane }\end{array}$} & \multirow[t]{4}{*}{2} & & Assistance/Supervision & 2 \\
\hline & & & & Dependent & 3 \\
\hline & & & Financial management & Independent & 1 \\
\hline & & & & Assistance/Supervision & 2 \\
\hline \multirow{3}{*}{$\begin{array}{l}\text { Bathroom } \\
\text { DME }\end{array}$} & None & 1 & & Dependent & 3 \\
\hline & Shower-chair/Tub-bench/GBs & 2 & Health/Med management & Independent & 1 \\
\hline & & & & Assistance/Supervision & 2 \\
\hline \multirow[t]{4}{*}{ \# ER Visits 1 year } & 0 & 1 & & Dependent & 3 \\
\hline & 1 & 2 & Number of medications & None & 1 \\
\hline & 2 & 3 & & $1-3$ & 2 \\
\hline & 3 or more & 4 & & 4 or more & 3 \\
\hline \multirow[t]{4}{*}{$\begin{array}{l}\text { \# Primary care visits } 1 \\
\text { yr. }\end{array}$} & $<1$ & 1 & Medication compliance & Yes & 1 \\
\hline & $1-3$ & 2 & & No & 2 \\
\hline & $4-6$ & 3 & $\begin{array}{l}\text { Medical apt. } \\
\text { compliance }\end{array}$ & Yes & 1 \\
\hline & $7+$ & 4 & & No & 2 \\
\hline \multirow[t]{2}{*}{ Acute or Chronic } & Acute & 1 & Housework/Laundry & Independent & 1 \\
\hline & Chronic & 2 & & Assistance/Supervision & 2 \\
\hline \multirow[t]{3}{*}{ Getting in/out bed } & Independent & 1 & & Dependent & 3 \\
\hline & Assistance/Supervision & 2 & Grocery shopping & Independent & 1 \\
\hline & Dependent & 3 & & Assistance/Supervision & 2 \\
\hline \multirow[t]{3}{*}{$\begin{array}{l}\text { Get in/out } \\
\text { bath/shower }\end{array}$} & Independent & 1 & & Dependent & 3 \\
\hline & Assistance/Supervision & 2 & Getting ready for bed & Independent & 1 \\
\hline & Dependent & 3 & & Assistance/Supervision & 2 \\
\hline \multirow[t]{3}{*}{ Bathing } & Independent & 1 & & Dependent & 3 \\
\hline & Assistance/Supervision & 2 & Number hours sleep/night & $1-5$ & 1 \\
\hline & Dependent & 3 & & $6-8$ & 2 \\
\hline \multirow[t]{3}{*}{$\begin{array}{l}\text { Upper body } \\
\text { dressing }\end{array}$} & Independent & 1 & & $>8$ & 3 \\
\hline & Assistance/Supervision & 2 & Feel well-rested & Yes & 1 \\
\hline & Dependent & 3 & & No & 2 \\
\hline
\end{tabular}


Table 1 Cont'd.

\begin{tabular}{|c|c|c|}
\hline Variable & Response & Code \\
\hline \multirow[t]{3}{*}{$\begin{array}{l}\text { Lower body } \\
\text { dressing }\end{array}$} & Independent & 1 \\
\hline & Assistance/Supervision & 2 \\
\hline & Dependent & 3 \\
\hline \multirow[t]{3}{*}{ Grooming/hygiene } & Independent & 1 \\
\hline & Assistance/Supervision & 2 \\
\hline & Dependent & 3 \\
\hline \multirow[t]{3}{*}{ Getting on/off toilet } & Independent & 1 \\
\hline & Assistance/Supervision & 2 \\
\hline & Dependent & 3 \\
\hline \multirow[t]{2}{*}{ Sensation changes } & Yes & 1 \\
\hline & No & 2 \\
\hline \multirow[t]{3}{*}{$\begin{array}{l}\text { Sensation affect } \\
\text { occupations }\end{array}$} & Yes & 1 \\
\hline & No & 2 \\
\hline & NA & 3 \\
\hline \multirow[t]{2}{*}{ Loss of strength } & Yes & 1 \\
\hline & No & 2 \\
\hline \multirow[t]{3}{*}{$\begin{array}{l}\text { Strength affect } \\
\text { occupations }\end{array}$} & Yes & 1 \\
\hline & No & 2 \\
\hline & NA & 3 \\
\hline \multirow[t]{2}{*}{$\begin{array}{l}\text { Unsteady/Loss of } \\
\text { balance }\end{array}$} & Yes & 1 \\
\hline & No & 2 \\
\hline \multirow[t]{3}{*}{ Number of times } & $1-2$ & 1 \\
\hline & $>2$ & 2 \\
\hline & NA & 3 \\
\hline \multirow[t]{3}{*}{ Negative Feelings } & Yes & 1 \\
\hline & Sometimes & 2 \\
\hline & Never & 3 \\
\hline \multirow[t]{3}{*}{$\begin{array}{l}\text { Memory } \\
\text { change/worse }\end{array}$} & Yes & 1 \\
\hline & Sometimes & 2 \\
\hline & Never & 3 \\
\hline
\end{tabular}

\begin{tabular}{|c|c|c|}
\hline Variable & Response & Code \\
\hline \multirow[t]{2}{*}{ Assist. Avail. $100 \%$ time } & Yes & 1 \\
\hline & No & 2 \\
\hline \multirow[t]{2}{*}{ Pain with activities } & Yes & 1 \\
\hline & No & 2 \\
\hline \multirow[t]{3}{*}{ Is pain being managed? } & Yes & 1 \\
\hline & No & 2 \\
\hline & NA & 3 \\
\hline \multirow[t]{2}{*}{ Shortness of breath } & Yes & 1 \\
\hline & No & 2 \\
\hline \multirow[t]{3}{*}{ Prefer to stay home } & Yes & 1 \\
\hline & Sometimes & 2 \\
\hline & Never & 3 \\
\hline \multirow[t]{3}{*}{ Feeling energized } & Yes & 1 \\
\hline & Sometimes & 2 \\
\hline & Never & 3 \\
\hline \multirow[t]{2}{*}{ Fall at home } & Yes & 1 \\
\hline & No & 2 \\
\hline \multirow[t]{4}{*}{ Number of times } & 1 & 1 \\
\hline & 2 & 2 \\
\hline & 3 or more & 3 \\
\hline & NA & 4 \\
\hline \multirow[t]{3}{*}{ Unhappy } & Yes & 1 \\
\hline & Sometimes & 2 \\
\hline & Never & 3 \\
\hline \multirow[t]{3}{*}{ Feels no one cares } & Yes & 1 \\
\hline & Sometimes & 2 \\
\hline & Never & 3 \\
\hline \multirow[t]{2}{*}{$\begin{array}{l}\text { Emergency/safety } \\
\text { check }\end{array}$} & Appropriate & 1 \\
\hline & Inappropriate & 2 \\
\hline
\end{tabular}


Table 2.

Individual OPAPC responses on Microsoft Excel (Viewing patients 1 through 25 out of 150)

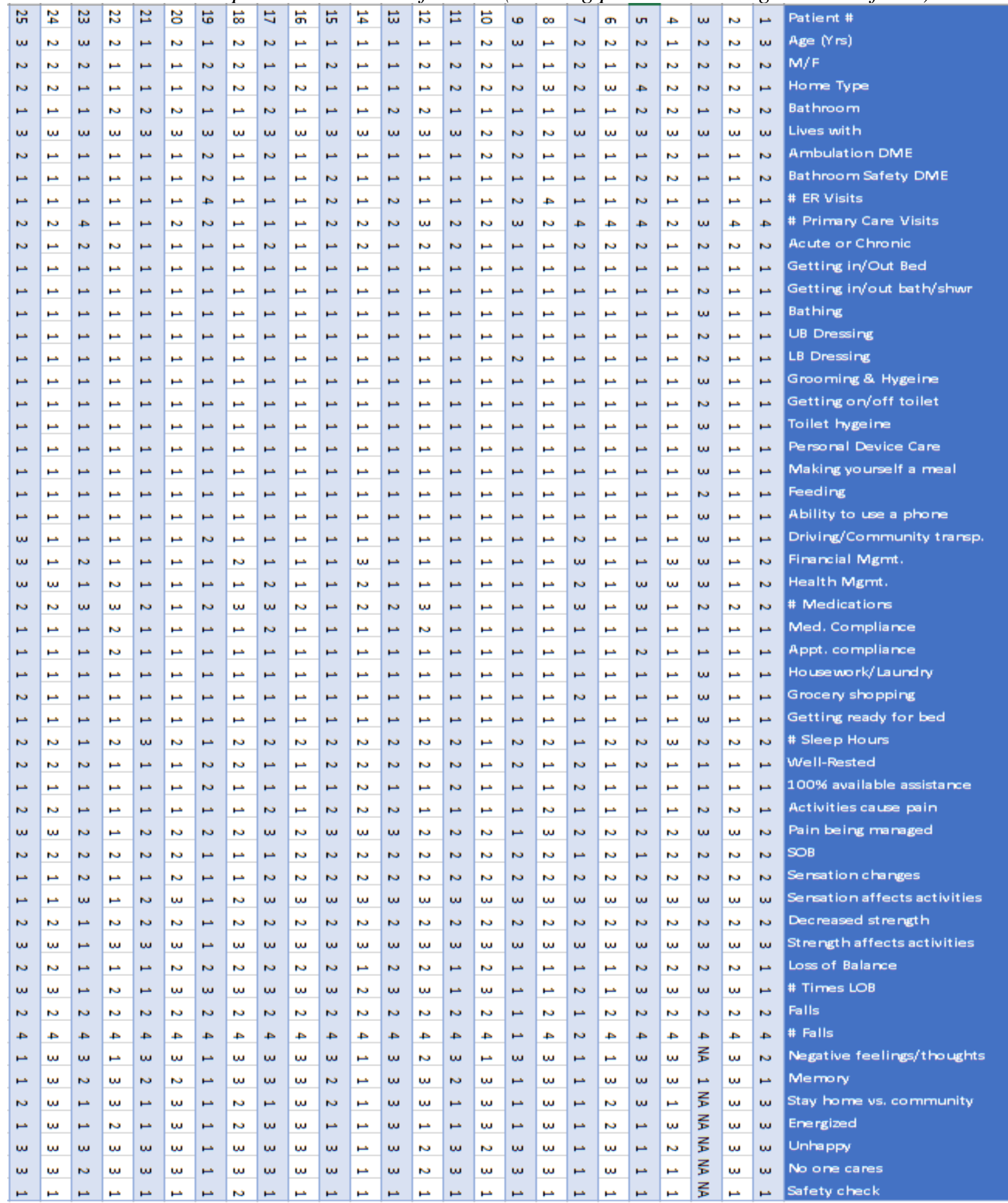




\section{Results}

\section{Patient Participants}

Results from the first set of data collection of patients were organized using Tables 3 and 4 below. Results were as follows:

\section{Safety.}

- 34 of the 66 participants who reported balance and/or fall issues use a bathtub with no bathroom durable medical equipment (DME) for safety.

- 42 of the 66 participants who reported balance and/or fall issues do not use DME for ambulation safety.

- Of the 50 older adult participants, $64 \%$ reported a loss of balance in the past week and $30 \%$ reported a fall in the past year.

- Out of 150 total participants, 8 reported an inappropriate response to the emergency/safety question, "If you were home alone, and there was an emergency such as your kitchen caught fire, what would you do?"

\section{ADLs.}

- Out of the 54 participants who require either some or total assistance for a single or multiple ADL/IADL(s), 20 of them reported not always having someone available to help them.

- Shortness of breath while performing daily occupations affected the middle-aged and older-adult age groups the most, with $32 \%$ of participants affected in each age-group. 
- Sensation deficits, such as numbness and/or tingling, was reported to affect $47 \%$ of participants, with $81 \%$ reporting that this deficit affects completing their valued occupations.

- Loss of strength was reported to affect $58 \%$ of older adults, $38 \%$ of middle-aged adults, and $30 \%$ of young adults. Of those participants who reported loss of strength in all age groups, $94 \%$ reported this deficit affecting their ability to complete their valued daily occupations.

- Out of all the older-adult participants, $25 \%$ reported they require either some or total assistance for their daily activities, while approximately $8 \%$ of middle-aged participants as well as the young adults reported they require either some or total assistance for daily activities.

- Approximately $18 \%$ of older adults require some or total assistance for functional transfers to include getting in/out of bed, getting in/out shower/tub, and getting on/off the toilet.

- For all age groups, there was a greater difficulty completing lower body dressing compared to upper body dressing, with the more significant difference being that of the older-adults with $12 \%$ reported required some or total assistance for upper body dressing while $28 \%$ reported requiring some or total assistance for lower body dressing.

\section{Sleep.}

- Regardless of the average amount of sleep hours reported, 51\% of participants reported not feeling well-rested, with $35 \%$ of participants reporting sleeping 
between 1-5 hours a night, 57\% reporting sleeping 6-8 hours per night, and 8\% reported sleeping greater than 8 hours per night.

\section{Pain.}

- Of the $63 \%$ of participants who reported having pain on any or multiple body parts/areas during their daily occupations, $89 \%$ reported the pain is not currently being managed.

\section{Mental health.}

- Mental health: $38 \%$ of all participants have stopped participating in valued occupations due to negative thoughts and/or feelings. Of the older-adult participants, $42 \%$ reported this as true.

- Of all the participants, $40 \%$ reported a change or worsening in their memory, with specifically $58 \%$ of older adults reporting this as true.

- Approximately $37 \%$ of all participants reported feeling unhappy with their lives, while $32 \%$ of all participants felt that they had no one that cares about them.

- All age groups had participants report mental health concerns, however middleaged participants reported the highest numbers of mental health concerns.

\section{IADLs.}

- Making a meal for oneself was reported as an activity that $30 \%$ of older adults required some or total assistance with.

- All age groups had participants who reported requiring some or total assistance for transportation and transportation arrangements, with $42 \%$ of older adults, $18 \%$ of middle-aged adults, and $16 \%$ of young adults. 
- Many older adults (48\%) reported not being able to manage their own finances including bill-payment schedules.

- While $41 \%$ of all participants reported taking between 1-3 medications, $38 \%$ of all participants reported taking over 4 medications. There was a total of $18 \%$ of all participants who reported not being compliant with their medication regimen.

- Other themes noted, but not calculated: Caregiver fatigue and stress

\section{Case examples.}

1. Patient $\mathrm{W}$ is a middle-aged adult who suffers from anxiety. Patient $\mathrm{W}$ reports going to the grocery store and forgetting to buy important items because they are focusing on their anxiety.

2. Patient $\mathrm{X}$ is an older adult who reports various falls over the past year as well as loss of balance at various times throughout the week. Patient $\mathrm{X}$ has a bathtub with no shower chair and relies on the wall and shower curtain to get in and out of the shower.

3. Patient $\mathrm{Y}$ is a middle-aged adult who is wheelchair bound. Patient $\mathrm{Y}$ is completely dependent upon their spouse for all functional transfers. Patient Y reports falls when being transferred onto a toilet and into a bathtub. Patient Y reports having okay upper-body strength, but reports wishing to be stronger as their spouse gets very fatigued and pained when lifting them.

4. Patient $\mathrm{Z}$ has a referral to pain management and isn't scheduled until 4 months out. Patient $\mathrm{Z}$ is worried about how they will be able to complete their valued activities while their pain is not being controlled. 
Table 3.

OPAPC Results

\begin{tabular}{|c|c|c|c|c|c|c|c|c|}
\hline Category & Response & $\begin{array}{c}\# \\
\text { Young } \\
\text { Adults } \\
(\mathbf{n}=\mathbf{5 0})\end{array}$ & $\%$ & $\begin{array}{c}\text { \# Middle- } \\
\text { aged } \\
\text { Adults } \\
(\mathbf{n}=\mathbf{5 0})\end{array}$ & $\%$ & $\begin{array}{c}\text { \# OLDER } \\
\text { ADULTS } \\
(\mathbf{n}=\mathbf{5 0})\end{array}$ & $\%$ & $\begin{array}{c}\text { \% of Total \# of } \\
\text { Participants } \\
(n=150)\end{array}$ \\
\hline \multirow[t]{2}{*}{ Sex } & Male & 14 & $28 \%$ & 26 & $52 \%$ & 22 & $44 \%$ & $41 \%$ \\
\hline & Female & 36 & $72 \%$ & 24 & $48 \%$ & 28 & $56 \%$ & $59 \%$ \\
\hline \multirow[t]{4}{*}{ Home Type } & House & 16 & $32 \%$ & 23 & $46 \%$ & 33 & $66 \%$ & $48 \%$ \\
\hline & Condo/Apartment & 32 & $64 \%$ & 20 & $40 \%$ & 14 & $28 \%$ & $44 \%$ \\
\hline & Mobile home & 2 & $4 \%$ & 5 & $10 \%$ & 3 & $6 \%$ & $7 \%$ \\
\hline & Homeless/Other & 0 & $0 \%$ & 2 & $4 \%$ & 0 & $0 \%$ & $1 \%$ \\
\hline \multirow[t]{2}{*}{ Bathroom } & Bathtub & 39 & $78 \%$ & 29 & $58 \%$ & 30 & $60 \%$ & $65 \%$ \\
\hline & Walk-in Shower & 11 & $22 \%$ & 21 & $42 \%$ & 20 & $40 \%$ & $35 \%$ \\
\hline \multirow[t]{4}{*}{ Lives (with) } & Alone & 3 & $6 \%$ & 3 & $6 \%$ & 7 & $14 \%$ & $9 \%$ \\
\hline & Spouse only & 4 & $8 \%$ & 8 & $16 \%$ & 10 & $20 \%$ & $15 \%$ \\
\hline & $\begin{array}{l}\text { Family/Friends } \\
\text { (multiple) }\end{array}$ & 43 & $86 \%$ & 39 & $78 \%$ & 34 & $68 \%$ & $77 \%$ \\
\hline & Caregiver & 0 & $0 \%$ & 0 & $0 \%$ & 0 & $0 \%$ & $0 \%$ \\
\hline \multirow{2}{*}{$\begin{array}{l}\text { Own Ambulation DME } \\
\text { (Wheelchair, Front- } \\
\text { wheeled walker, 4- } \\
\text { wheeled walker, Cane) }\end{array}$} & None & 44 & $88 \%$ & 38 & $76 \%$ & 26 & $52 \%$ & $72 \%$ \\
\hline & Yes, one or more & 6 & $12 \%$ & 12 & $24 \%$ & 24 & $48 \%$ & $28 \%$ \\
\hline \multirow{2}{*}{$\begin{array}{l}\text { Own Bathroom safety } \\
\text { DME } \\
\text { (Shower chair, Tub- } \\
\text { bench, grab-bars, toilet } \\
\text { rails) }\end{array}$} & None & 45 & $90 \%$ & 42 & $84 \%$ & 35 & $70 \%$ & $81 \%$ \\
\hline & Yes, one or more & 5 & $10 \%$ & 8 & $16 \%$ & 15 & $30 \%$ & $28 \%$ \\
\hline \multirow[t]{4}{*}{ \# ER visits past 1 year } & 0 & 29 & $58 \%$ & 28 & $56 \%$ & 29 & $58 \%$ & $57 \%$ \\
\hline & 1 & 12 & $24 \%$ & 15 & $30 \%$ & 18 & $36 \%$ & $30 \%$ \\
\hline & 2 & 2 & $4 \%$ & 5 & $10 \%$ & 3 & $6 \%$ & $7 \%$ \\
\hline & $3+$ & 7 & $14 \%$ & 2 & $4 \%$ & 0 & $0 \%$ & $6 \%$ \\
\hline \multirow[t]{4}{*}{$\begin{array}{l}\text { \# Primary Care visits } \\
\text { past } 1 \text { year }\end{array}$} & $<1$ & 12 & $24 \%$ & 8 & $16 \%$ & 2 & $4 \%$ & $15 \%$ \\
\hline & $1-3$ & 18 & $36 \%$ & 17 & $34 \%$ & 12 & $24 \%$ & $31 \%$ \\
\hline & $4-6$ & 12 & $24 \%$ & 14 & $28 \%$ & 18 & $36 \%$ & $29 \%$ \\
\hline & $7+$ & 8 & $16 \%$ & 11 & $22 \%$ & 18 & $36 \%$ & $25 \%$ \\
\hline \multirow[t]{2}{*}{ Acute or Chronic } & Acute & 32 & $64 \%$ & 17 & $34 \%$ & 4 & $8 \%$ & $35 \%$ \\
\hline & Chronic & 18 & $36 \%$ & 33 & $66 \%$ & 46 & $92 \%$ & $65 \%$ \\
\hline \multirow{3}{*}{$\begin{array}{l}\text { ADL/IADL assistance } \\
\text { levels } \\
\text { (See ADL/IADL chart } \\
\text { for breakdown of } \\
\text { individual ADL/IADLs) }\end{array}$} & Independent & --- & $92 \%$ & --- & $91.8 \%$ & --- & $75 \%$ & \multirow{3}{*}{$\begin{array}{l}\text { (See ADL/IADL } \\
\text { chart for data) }\end{array}$} \\
\hline & $\begin{array}{l}\text { Requires Assist or } \\
\text { Supervision }\end{array}$ & --- & $4.3 \%$ & --- & $4.7 \%$ & --- & $13 \%$ & \\
\hline & Dependent & --- & $3.7 \%$ & --- & $3.5 \%$ & --- & $12 \%$ & \\
\hline \multirow[t]{3}{*}{ \# Medications } & None & 17 & $34 \%$ & 12 & $24 \%$ & 3 & $6 \%$ & $21 \%$ \\
\hline & $1-3$ & 24 & $48 \%$ & 18 & $36 \%$ & 19 & $38 \%$ & $41 \%$ \\
\hline & $4+$ & 9 & $18 \%$ & 20 & $40 \%$ & 28 & $56 \%$ & $38 \%$ \\
\hline \multirow[t]{2}{*}{ Medication Compliance } & Yes & 42 & $84 \%$ & 41 & $82 \%$ & 40 & $80 \%$ & $82 \%$ \\
\hline & No & 8 & $16 \%$ & 9 & $18 \%$ & 10 & $20 \%$ & $18 \%$ \\
\hline \multirow[t]{2}{*}{$\begin{array}{l}\text { Medical Appointment } \\
\text { Compliance }\end{array}$} & Yes & 45 & $90 \%$ & 44 & $88 \%$ & 50 & $100 \%$ & $93 \%$ \\
\hline & No & 5 & $10 \%$ & 6 & $12 \%$ & 0 & $0 \%$ & $7 \%$ \\
\hline \multirow[t]{3}{*}{$\begin{array}{l}\text { Average \# hours sleep } \\
\text { per night }\end{array}$} & $1-5$ & 15 & $30 \%$ & 15 & $30 \%$ & 22 & $44 \%$ & $35 \%$ \\
\hline & $6-8$ & 31 & $62 \%$ & 33 & $66 \%$ & 22 & $44 \%$ & $57 \%$ \\
\hline & $>8$ & 4 & $8 \%$ & 2 & $4 \%$ & 6 & $12 \%$ & $8 \%$ \\
\hline \multirow[t]{2}{*}{ Well-Rested? } & Yes & 22 & $44 \%$ & 25 & $50 \%$ & 30 & $60 \%$ & $51 \%$ \\
\hline & No & 28 & $56 \%$ & 25 & $50 \%$ & 20 & $40 \%$ & $49 \%$ \\
\hline
\end{tabular}


Table 3 Cont'd.

\begin{tabular}{|c|c|c|c|c|c|c|c|c|}
\hline $\begin{array}{l}\text { If needed, is assistance } \\
\text { available } 100 \% \text { of the } \\
\text { time? }\end{array}$ & Yes & 43 & $86 \%$ & 43 & $86 \%$ & 42 & $84 \%$ & $85 \%$ \\
\hline & No & 7 & $14 \%$ & 7 & $14 \%$ & 8 & $16 \%$ & $15 \%$ \\
\hline \multirow[t]{2}{*}{ Pain with activity } & Yes & 32 & $64 \%$ & 35 & $70 \%$ & 27 & $54 \%$ & $63 \%$ \\
\hline & No & 18 & $36 \%$ & 15 & $30 \%$ & 23 & $46 \%$ & $37 \%$ \\
\hline \multirow{2}{*}{$\begin{array}{l}\text { Of those who said yes, is } \\
\text { the pain being managed? }\end{array}$} & Yes & 1 & $3 \%$ & 6 & $17 \%$ & 3 & $11 \%$ & $11 \%$ \\
\hline & No & 31 & $97 \%$ & 29 & $83 \%$ & 24 & $89 \%$ & $89 \%$ \\
\hline \multirow[t]{2}{*}{$\begin{array}{l}\text { Shortness of breath with } \\
\text { activity }\end{array}$} & Yes & 9 & $18 \%$ & 16 & $32 \%$ & 16 & $32 \%$ & $27 \%$ \\
\hline & No & 41 & $82 \%$ & 34 & $68 \%$ & 34 & $68 \%$ & $73 \%$ \\
\hline \multirow[t]{2}{*}{ Sensation deficits } & Yes & 21 & $42 \%$ & 23 & $46 \%$ & 26 & $52 \%$ & $47 \%$ \\
\hline & No & 29 & $58 \%$ & 27 & $54 \%$ & 24 & $48 \%$ & $53 \%$ \\
\hline \multirow{2}{*}{$\begin{array}{l}\text { Of those who said yes, } \\
\text { are any sensation deficits } \\
\text { affecting activity? }\end{array}$} & Yes & 18 & $86 \%$ & 19 & $83 \%$ & 21 & $42 \%$ & $81 \%$ \\
\hline & No & 3 & $14 \%$ & 4 & $17 \%$ & 5 & $10 \%$ & $19 \%$ \\
\hline \multirow[t]{2}{*}{ Loss of strength } & Yes & 15 & $30 \%$ & 19 & $38 \%$ & 29 & $58 \%$ & $42 \%$ \\
\hline & No & 35 & $70 \%$ & 31 & $62 \%$ & 21 & $42 \%$ & $58 \%$ \\
\hline \multirow{2}{*}{$\begin{array}{l}\text { Of those who said yes, } \\
\text { does loss of strength } \\
\text { affect activity? }\end{array}$} & Yes & 15 & $100 \%$ & 18 & $95 \%$ & 26 & $90 \%$ & $94 \%$ \\
\hline & No & 0 & $0 \%$ & 1 & $5 \%$ & 3 & $10 \%$ & $6 \%$ \\
\hline \multirow[t]{2}{*}{$\begin{array}{l}\text { Unsteady/Loss of } \\
\text { balance past } 1 \text { week }\end{array}$} & Yes & 10 & $20 \%$ & 18 & $36 \%$ & 32 & $64 \%$ & $40 \%$ \\
\hline & No & 40 & $80 \%$ & 32 & $64 \%$ & 18 & $36 \%$ & $60 \%$ \\
\hline \multirow{2}{*}{$\begin{array}{l}\text { Of those who have had } \\
\text { unsteady/LOB, \# times } \\
\text { in past } 1 \text { week }\end{array}$} & $1-2$ & 6 & $60 \%$ & 8 & $44 \%$ & 15 & $47 \%$ & $48 \%$ \\
\hline & $>2$ & 4 & $40 \%$ & 10 & $56 \%$ & 17 & $53 \%$ & $52 \%$ \\
\hline \multirow[t]{2}{*}{ Fall(s) in past 1 year } & Yes & 6 & $12 \%$ & 10 & $20 \%$ & 15 & $30 \%$ & $21 \%$ \\
\hline & No & 44 & $88 \%$ & 40 & $80 \%$ & 35 & $70 \%$ & $79 \%$ \\
\hline \multirow{3}{*}{$\begin{array}{l}\text { Of those who have } \\
\text { fallen, \# times in past } 1 \\
\text { year }\end{array}$} & 1 & 3 & $50 \%$ & 4 & $40 \%$ & 9 & $60 \%$ & $52 \%$ \\
\hline & 2 & 2 & $33 \%$ & 2 & $20 \%$ & 3 & $20 \%$ & $22 \%$ \\
\hline & $3+$ & 1 & $17 \%$ & 4 & $40 \%$ & 3 & $20 \%$ & $26 \%$ \\
\hline \multirow[t]{3}{*}{ Negative feelings } & Yes/Sometimes & 16 & $32 \%$ & 20 & $40 \%$ & 21 & $42 \%$ & $38 \%$ \\
\hline & No & 34 & $68 \%$ & 29 & $58 \%$ & 28 & $56 \%$ & $61 \%$ \\
\hline & NA & 0 & $0 \%$ & 1 & $2 \%$ & 1 & $2 \%$ & $1 \%$ \\
\hline \multirow[t]{3}{*}{ Memory changes/worse } & Yes/Sometimes & 13 & $26 \%$ & 18 & $36 \%$ & 29 & $58 \%$ & $40 \%$ \\
\hline & No & 37 & $74 \%$ & 32 & $64 \%$ & 20 & $40 \%$ & $59.3 \%$ \\
\hline & NA & 0 & $0 \%$ & 0 & $0 \%$ & 1 & $2 \%$ & $0.7 \%$ \\
\hline \multirow[t]{3}{*}{ Prefer to stay home } & Yes/Sometimes & 21 & $42 \%$ & 22 & $44 \%$ & 18 & $36 \%$ & $40.7 \%$ \\
\hline & No & 29 & $58 \%$ & 27 & $54 \%$ & 31 & $62 \%$ & $58 \%$ \\
\hline & NA & 0 & $0 \%$ & 1 & $2 \%$ & 1 & $2 \%$ & $1.3 \%$ \\
\hline \multirow[t]{3}{*}{$\begin{array}{l}\text { Difficulty feeling } \\
\text { energized }\end{array}$} & Yes/Sometimes & 21 & $42 \%$ & 23 & $46 \%$ & 18 & $36 \%$ & $41.33 \%$ \\
\hline & No & 29 & $58 \%$ & 26 & $52 \%$ & 31 & $62 \%$ & $57.33 \%$ \\
\hline & $\mathrm{NA}$ & 0 & $0 \%$ & 1 & $2 \%$ & 1 & $2 \%$ & $1.33 \%$ \\
\hline \multirow[t]{3}{*}{ Unhappy } & Yes/Sometimes & 16 & $32 \%$ & 22 & $44 \%$ & 17 & $34 \%$ & $37 \%$ \\
\hline & No & 34 & $68 \%$ & 27 & $54 \%$ & 32 & $64 \%$ & $62 \%$ \\
\hline & $\mathrm{NA}$ & 0 & $0 \%$ & 1 & $2 \%$ & 1 & $2 \%$ & $1 \%$ \\
\hline \multirow[t]{3}{*}{$\begin{array}{l}\text { Feels no one cares for } \\
\text { them }\end{array}$} & Yes/Sometimes & 15 & $30 \%$ & 17 & $34 \%$ & 16 & $32 \%$ & $32 \%$ \\
\hline & No & 35 & $70 \%$ & 32 & $64 \%$ & 33 & $66 \%$ & $66.66 \%$ \\
\hline & NA & 0 & $0 \%$ & 1 & $2 \%$ & 1 & $2 \%$ & $1.33 \%$ \\
\hline \multirow[t]{3}{*}{ Emergency/Safety check } & Appropriate & 50 & $100 \%$ & 47 & $94 \%$ & 43 & $86 \%$ & $93.33 \%$ \\
\hline & Inappropriate & 0 & $0 \%$ & 2 & $4 \%$ & 6 & $12 \%$ & $5.33 \%$ \\
\hline & $\mathrm{NA}$ & 0 & $0 \%$ & 1 & $2 \%$ & 1 & $2 \%$ & $1.33 \%$ \\
\hline
\end{tabular}


Table 4.

Results for Individual ADL/IADLs

\begin{tabular}{|c|c|c|c|c|c|c|c|c|}
\hline ADL/IADL & Assistance Level & $\begin{array}{c}\# \\
\text { Young } \\
\text { Adults } \\
\end{array}$ & $\%$ & $\begin{array}{c}\text { \# Middle- } \\
\text { aged Adults }\end{array}$ & $\%$ & $\begin{array}{c}\text { \# Older } \\
\text { Adults }\end{array}$ & $\%$ & $\begin{array}{c}\text { \% of Total \# of } \\
\text { Participants } \\
(n=150)\end{array}$ \\
\hline \multirow[t]{3}{*}{ Getting in/out bed } & Independent & 47 & $94 \%$ & 49 & $98 \%$ & 40 & $80 \%$ & $91 \%$ \\
\hline & $\begin{array}{l}\text { Requires assistance or } \\
\text { supervision }\end{array}$ & 1 & $2 \%$ & 1 & $2 \%$ & 9 & $18 \%$ & $7 \%$ \\
\hline & Dependent & 2 & $4 \%$ & 0 & $0 \%$ & 1 & $2 \%$ & $2 \%$ \\
\hline \multirow[t]{3}{*}{$\begin{array}{l}\text { Getting in/out } \\
\text { bath/shower }\end{array}$} & Independent & 47 & $94 \%$ & 46 & $92 \%$ & 38 & $76 \%$ & $87 \%$ \\
\hline & $\begin{array}{l}\text { Requires assistance or } \\
\text { supervision }\end{array}$ & 1 & $2 \%$ & 4 & $8 \%$ & 8 & $16 \%$ & $9 \%$ \\
\hline & Dependent & 2 & $4 \%$ & 0 & $0 \%$ & 4 & $8 \%$ & $4 \%$ \\
\hline \multirow[t]{3}{*}{ Bathing } & Independent & 46 & $92 \%$ & 46 & $92 \%$ & 41 & $82 \%$ & $89 \%$ \\
\hline & $\begin{array}{l}\text { Requires assistance or } \\
\text { supervision }\end{array}$ & 4 & $8 \%$ & 2 & $4 \%$ & 5 & $10 \%$ & $7 \%$ \\
\hline & Dependent & 0 & $0 \%$ & 2 & $4 \%$ & 4 & $8 \%$ & $4 \%$ \\
\hline \multirow[t]{3}{*}{ Upper Body Dressing } & Independent & 47 & $94 \%$ & 47 & $94 \%$ & 44 & $88 \%$ & $92 \%$ \\
\hline & $\begin{array}{l}\text { Requires assistance or } \\
\text { supervision }\end{array}$ & 3 & $6 \%$ & 3 & $6 \%$ & 3 & $6 \%$ & $6 \%$ \\
\hline & Dependent & 0 & $0 \%$ & 0 & $0 \%$ & 3 & $6 \%$ & $2 \%$ \\
\hline \multirow[t]{3}{*}{ Lower Body Dressing } & Independent & 46 & $92 \%$ & 46 & $92 \%$ & 36 & $72 \%$ & $85 \%$ \\
\hline & $\begin{array}{l}\text { Requires assistance or } \\
\text { supervision }\end{array}$ & 3 & $6 \%$ & 3 & $6 \%$ & 10 & $20 \%$ & $11 \%$ \\
\hline & Dependent & 1 & $2 \%$ & 1 & $2 \%$ & 4 & $8 \%$ & $4 \%$ \\
\hline \multirow[t]{3}{*}{ Grooming/Hygiene } & Independent & 47 & $94 \%$ & 47 & $94 \%$ & 44 & $88 \%$ & $92 \%$ \\
\hline & $\begin{array}{l}\text { Requires assistance or } \\
\text { supervision }\end{array}$ & 3 & $6 \%$ & 2 & $4 \%$ & 5 & $10 \%$ & $7 \%$ \\
\hline & Dependent & 0 & $0 \%$ & 1 & $2 \%$ & 1 & $2 \%$ & $1 \%$ \\
\hline \multirow[t]{3}{*}{ Getting on/off toilet } & Independent & 47 & $94 \%$ & 47 & $94 \%$ & 41 & $82 \%$ & $90 \%$ \\
\hline & $\begin{array}{l}\text { Requires assistance or } \\
\text { supervision }\end{array}$ & 2 & $4 \%$ & 3 & $6 \%$ & 7 & $14 \%$ & $8 \%$ \\
\hline & Dependent & 1 & $2 \%$ & 0 & $0 \%$ & 2 & $4 \%$ & $2 \%$ \\
\hline \multirow[t]{3}{*}{ Toilet hygiene } & Independent & 47 & $94 \%$ & 48 & $96 \%$ & 40 & $80 \%$ & $90 \%$ \\
\hline & $\begin{array}{l}\text { Requires assistance or } \\
\text { supervision }\end{array}$ & 3 & $6 \%$ & 1 & $2 \%$ & 6 & $12 \%$ & $7 \%$ \\
\hline & Dependent & 0 & $0 \%$ & 1 & $2 \%$ & 4 & $8 \%$ & $3 \%$ \\
\hline \multirow[t]{3}{*}{ Personal device care } & Independent & 46 & $92 \%$ & 47 & $96 \%$ & 41 & $82 \%$ & $89.3 \%$ \\
\hline & $\begin{array}{l}\text { Requires assistance or } \\
\text { supervision }\end{array}$ & 3 & $6 \%$ & 2 & $4 \%$ & 7 & $14 \%$ & $8 \%$ \\
\hline & Dependent & 1 & $2 \%$ & 1 & $2 \%$ & 2 & $4 \%$ & $2.7 \%$ \\
\hline \multirow[t]{3}{*}{ Making self a meal } & Independent & 47 & $94 \%$ & 46 & $92 \%$ & 35 & $70 \%$ & $85 \%$ \\
\hline & $\begin{array}{l}\text { Requires assistance or } \\
\text { supervision }\end{array}$ & 0 & $0 \%$ & 3 & $6 \%$ & 7 & $14 \%$ & $7 \%$ \\
\hline & Dependent & 3 & $6 \%$ & 1 & $2 \%$ & 8 & $16 \%$ & $8 \%$ \\
\hline \multirow[t]{3}{*}{ Feeding } & Independent & 50 & $100 \%$ & 49 & $98 \%$ & 48 & $96 \%$ & $98 \%$ \\
\hline & $\begin{array}{l}\text { Requires assistance or } \\
\text { supervision }\end{array}$ & 0 & $0 \%$ & 1 & $2 \%$ & 0 & $0 \%$ & $0.7 \%$ \\
\hline & Dependent & 0 & $0 \%$ & 0 & $0 \%$ & 2 & $4 \%$ & $1.3 \%$ \\
\hline \multirow[t]{3}{*}{ Phone use } & Independent & 50 & $100 \%$ & 49 & $98 \%$ & 38 & $76 \%$ & $91.33 \%$ \\
\hline & $\begin{array}{l}\text { Requires assistance or } \\
\text { supervision }\end{array}$ & 0 & $0 \%$ & 0 & $0 \%$ & 8 & $16 \%$ & $5.33 \%$ \\
\hline & Dependent & 0 & $0 \%$ & 1 & $2 \%$ & 4 & $8 \%$ & $3.33 \%$ \\
\hline \multirow[t]{3}{*}{$\begin{array}{l}\text { Driving/community } \\
\text { transport }\end{array}$} & Independent & 42 & $84 \%$ & 41 & $82 \%$ & 29 & $58 \%$ & $75 \%$ \\
\hline & $\begin{array}{l}\text { Requires assistance or } \\
\text { supervision }\end{array}$ & 1 & $2 \%$ & 1 & $2 \%$ & 1 & $2 \%$ & $2 \%$ \\
\hline & Dependent & 7 & $14 \%$ & 8 & $16 \%$ & 20 & $40 \%$ & $23 \%$ \\
\hline
\end{tabular}


Table 4 Cont'd.

\begin{tabular}{|c|c|c|c|c|c|c|c|c|}
\hline Financial mgmt. & Independent & 40 & $80 \%$ & 41 & $82 \%$ & 26 & $52 \%$ & $71 \%$ \\
\hline & $\begin{array}{l}\text { Requires assistance or } \\
\text { supervision }\end{array}$ & 3 & $6 \%$ & 3 & $6 \%$ & 7 & $14 \%$ & $9 \%$ \\
\hline & Dependent & 7 & $14 \%$ & 6 & $12 \%$ & 17 & $34 \%$ & $20 \%$ \\
\hline \multirow[t]{3}{*}{ Health mgmt. } & Independent & 40 & $80 \%$ & 40 & $80 \%$ & 28 & $56 \%$ & $72 \%$ \\
\hline & $\begin{array}{l}\text { Requires assistance or } \\
\text { supervision }\end{array}$ & 9 & $18 \%$ & 5 & $10 \%$ & 7 & $14 \%$ & $21 \%$ \\
\hline & Dependent & 1 & $2 \%$ & 5 & $10 \%$ & 15 & $30 \%$ & $14 \%$ \\
\hline \multirow[t]{3}{*}{ Housework } & Independent & 46 & $92 \%$ & 47 & $94 \%$ & 36 & $72 \%$ & $86 \%$ \\
\hline & $\begin{array}{l}\text { Requires assistance or } \\
\text { supervision }\end{array}$ & 0 & $0 \%$ & 2 & $4 \%$ & 7 & $14 \%$ & $6 \%$ \\
\hline & Dependent & 4 & $8 \%$ & 1 & $2 \%$ & 7 & $14 \%$ & $8 \%$ \\
\hline \multirow[t]{3}{*}{ Grocery shopping } & Independent & 45 & $90 \%$ & 43 & $86 \%$ & 33 & $66 \%$ & $80.7 \%$ \\
\hline & $\begin{array}{l}\text { Requires assistance or } \\
\text { supervision }\end{array}$ & 1 & $2 \%$ & 4 & $8 \%$ & 6 & $12 \%$ & $7.3 \%$ \\
\hline & Dependent & 4 & $8 \%$ & 3 & $6 \%$ & 12 & $24 \%$ & $13 \%$ \\
\hline \multirow{2}{*}{ Getting ready for bed } & $\begin{array}{l}\text { Requires assistance or } \\
\text { supervision }\end{array}$ & 2 & $4 \%$ & 2 & $4 \%$ & 10 & $20 \%$ & $9 \%$ \\
\hline & Dependent & 1 & $2 \%$ & 1 & $2 \%$ & 1 & $2 \%$ & $2 \%$ \\
\hline
\end{tabular}

\section{Referrals to Occupational Therapy}

Additional observations of the clinic's daily processes included looking into the electronic health record system to make note of how the process of occupational therapy referrals have been processed in the past two years. A two-year search was chosen as a base for all data searches for consistency. Upon initiation of this search, it was learned that occupational therapy is not listed as a referral source. This means, that primary care providers have not been able to refer a patient directly to occupational therapy since the launch of the electronic health system of Borrego Health. The current process the referring providers follow include choosing "occupational medicine" from the referral source drop-down menu and if occupational therapy is the goal for the patient, the provider might type in "OT" in an open space for additional notes. Some occupational therapy referrals, under this process, are sent to rehabilitation locations that don't provide occupational therapy services, so the referral gets sent back to the Borrego referrals department and is redirected to another location. Upon informing the Director of 
Medical Staff Services of this discrepancy, it was decided by Borrego Health management to add occupational therapy as a referral source come September 2019, when Borrego Health upgrades their electronic health system.

Through a comprehensive search done by the referrals department head, it was found that there was a total of 185 occupational therapy referrals generated from April 2017 to April 2019. This number was generated using a search criterion including the terms "occupational medicine." This search criteria consisted of all Borrego Health locations in southern California where over 250 doctors, physician assistants, and nurse practitioners who can refer patients to outside specialists have been and currently are employed. This number reflects both adult and children occupational therapy referrals, with the majority ordered being for children. The exact number ordered for adults and children was not given. Through this examination of individual occupational therapy referrals, it was learned that many adult referrals to occupational therapy were cancelled. Reasons for cancelled occupational therapy referrals include the patient did not show to their scheduled appointment, the patient kept their physical therapy appointment but cancelled their occupational therapy appointment as it was thought to not be needed, and the patient refused to schedule with occupational therapy. It cannot be confirmed that these said referrals were indeed send to occupational therapy or occupational medicine due to limited access to this information.

\section{Healthcare Staff Participants}

Once the patient surveys were analyzed, the student presented results as well as a clear description about the value and potential role that occupational therapy can have in the primary care setting to the healthcare staff. A print-out of the presentation was left with healthcare staff 
(Appendix C), and a more in-depth information packet was left with all of the primary care providers (Appendix D). The Healthcare Staff Survey (Appendix E) was given after the presentation during a monthly staff meeting at Centro Medico Escondido site. There were approximately 50 attendees of this staff meeting which included medical assistants, front desk staff, nurses, physicians, lab workers, managers, and security staff. There were 22 people who participated in the post-presentation survey. There was a total of 5 primary care providers who filled out the survey which was made up of 1 physician assistant (PA), 1 Doctor of Osteopathic Medicine (DO), and 3 medical doctors (MD). There was a total of 17 survey responses from other healthcare staff which were comprised of 9 medical assistants (MA), 1 nurse (RN), 4 referrals case coordinators (RCC), 1 patient service representative (PSR), and 2 who marked their profession as "other" with a blank job description. Results from the second set of data collection from healthcare staff were organized into Table 5 below.

Table 5.

Post-Presentation Healthcare Staff Survey Results

\begin{tabular}{|c|c|c|c|}
\hline Question & $\begin{array}{l}\text { Providers; } \mathrm{n}=5 \\
(\mathrm{DO}, \mathrm{MD}, \mathrm{PA})\end{array}$ & $\begin{array}{l}\text { Other healthcare } \\
\text { staff; } \mathrm{n}=17 \\
\text { (RN, MA, etc.) }\end{array}$ & $\begin{array}{l}\text { Total staff; } \\
\mathrm{n}=22\end{array}$ \\
\hline $\begin{array}{l}\text { Do you agree that you understand the potential role } \\
\text { of occupational therapy in primary care? }\end{array}$ & $\begin{array}{l}\text { Yes.............20\% } \\
\text { Somewhat......80\% } \\
\text { No }\end{array}$ & $\begin{array}{l}\text { Yes ..........53\% } \\
\text { Somewhat....47\% } \\
\text { No }\end{array}$ & $\begin{array}{l}\text { Yes...........45\% } \\
\text { Somewhat...55\% } \\
\text { No }\end{array}$ \\
\hline $\begin{array}{l}\text { Can you envision patients in this clinic that you } \\
\text { believe would benefit from the skill set of an } \\
\text { occupational therapist? }\end{array}$ & $\begin{array}{l}\text { Yes...........100\% } \\
\text { Possibly } \\
\text { No }\end{array}$ & $\begin{array}{l}\text { Yes..........88\% } \\
\text { Possibly...... 12\% } \\
\text { No }\end{array}$ & $\begin{array}{l}\text { Yes..........91\% } \\
\text { Possibly.......9\% } \\
\text { No }\end{array}$ \\
\hline $\begin{array}{l}\text { Do you feel that you have enough time to address } \\
\text { all patient concerns during a regular office visit? }\end{array}$ & $\begin{array}{l}\text { Always } \\
\text { Sometimes....100\% } \\
\text { Never }\end{array}$ & \multirow{2}{*}{\multicolumn{2}{|c|}{$\begin{array}{l}\text { NA (These } 2 \text { questions were only } \\
\text { asked to providers) }\end{array}$}} \\
\hline $\begin{array}{l}\text { Would you be open to working with an } \\
\text { occupational therapist as a member of your } \\
\text { interprofessional care team? }\end{array}$ & $\begin{array}{l}\text { Yes...........100\% } \\
\text { Possibly } \\
\text { No }\end{array}$ & & \\
\hline
\end{tabular}

The following comments were left on healthcare staff surveys:

- "Clinic will greatly benefit from an OT on site." -MD 
- "We need OT on staff in primary care. We are missing a lot of quality care." -MD

- "It would be great to have OT on board for both adults and minors." - DO

- "We need to have OT services in the clinic because patients would greatly benefit from it. Patients won't have a delay of care and we won't lose the patient as well by having OT in clinic. There will be constant flow in patient care." -Referrals Care Coordinator

- "The geriatric population should be more aware of what OT can do for them or what it even is because some are not familiar with it." -Referrals Care Coordinator

\section{Current Assessments}

Another area of observation was the current assessment protocol for patients. The six documents used to assess new patients of Borrego Health are shown in Appendix F and are the Staying Healthy Assessment, Adult Medical History form, Vitals sheet, Tuberculosis Risk Assessment Screening, Depression Screening, and PHQ-9. The Staying Healthy Assessment is a questionnaire that asks about diet, exercise, abuse at home, dental care, smoking and alcohol history, sexual activity safety, etc. The Adult Medical History form is filled out by the patient and asks about conditions or diseases the patient might have, surgical history, family history, current medications, etc. The Vitals sheet is filled out by the medical assistant who measures the patient's weight, height, temperature, blood pressure, etc. The Tuberculosis (TB) Risk Assessment Screening form is filled out by the patient and asks about any recent trips out of the country, if they have ever had a positive TB test, and whether any TB symptoms are present. The Depression Screening is a 3-question form that the patient fills out that ask if depression symptoms are present and whether they have been referred to mental health services. If responses from this form are positive, then the patient is given the PHQ-9 form which asks more in-depth questions about depression symptoms. 


\section{Discussion}

The results from the patient interviews listed above demonstrate a need for occupational therapy in the adult primary care population. ADL/IADL dependence, balance and fall concerns, DME necessities, pain, poor sleep quality, and mental health are only a few common themes found in patient interviews that can be addressed by an occupational therapist. The case examples above came from real patient interviews. These examples can provide a greater sense of understanding as to how different factors can affect one's daily occupations.

The only screening amongst the current assessments at this primary care setting that ask about factors influencing or affecting one's ability to perform and complete their daily activities is in the PHQ-9 Depression screening form. A person's overall health includes their ability to complete their valued activities and assessments should be used that evaluate all health factors. There are various occupation-based assessments, for which occupational therapists use when assessing a patient. The Canadian Occupational Performance Measure (COPM) is an assessment tool that could be used in primary care that measures the patient's perspective of performance and satisfaction in daily activities (Donnelly et al., 2017). The Barthel Index is an assessment tool that is used to measure performance in ADLs and mobility (AOTA, 2013). Other occupation-based assessments include the Functional Reach Test, Berg Balance Scale, and the Executive Function Performance Test. The following is a list, taken from the Shirley Ryan AbilityLab (2019), of underlying factors and areas in which an occupational therapist can assess when a person's occupational engagement is compromised:

- Driving education

- Decision making

- Self-care

- Depression
- Reaction time

- Sensory

- Fine \& Gross motor

- Behavior
- Word finding

- Developmental milestones

- Visual-perceptual skill

- Range of motion 
- Strength

- Vestibular

- Sleep

- Processing speed

- Executive function

- Aphasia

- Dexterity

- Life participation

- Stress \& coping
- Self-efficacy

- Swallowing

- Reading comprehension

- Pain

- Cognition

- Balance non-vestibular

- Incontinence

- Negative affect

- Gait
- Upper extremity function

- Spasticity

- Motivation

- Dysarthria

- Attention \& working memory

- Communication

- Functional mobility

- Reasoning \& problem solving

- Touch

Results from the healthcare staff surveys suggest that although additional education on the scope of occupational therapy is required, there was a great majority $(91 \%)$ of staff who agreed that occupational therapy would benefit the primary care patients. An additional presentation or training including more content on the scope and history of occupational therapy with a case example for healthcare staff to discuss and work through would be another beneficial way to expand knowledge of occupational therapy practice. Providers who completed the survey $(n=5)$ all agreed that they do not always have enough time during an office visit to address all patient concerns. All of these providers also agreed that they would be open to welcoming an occupational therapist into their interprofessional care teams.

\section{Limitations/Barriers}

The fast-paced nature and limited time of primary care practice was a limiting factor concerning my introduction to the setting and dissemination of any and all information to healthcare staff. I was given the opportunity to introduce myself and the purpose of my project at a providers' meeting which is run by the medical director of the clinic and all of the clinics' providers were in attendance. However, only two minutes were allotted for this introduction. 
For the final dissemination of my findings, I presented to healthcare staff in July 2019. I was allotted a 10-minute time slot to discuss my project findings as well as educate them about occupational therapy. Time was a limitation as not all valuable information was shared. For example, 4 out of 22 results were shared due to this time constraint. Additional time could have allowed for a more in-depth explanation of occupational therapy and this capstone project, which in turn could have increased the number of participants who reported an overall understanding.

\section{Implications for Occupational Therapy}

While interviewing patients, I was able to learn about the areas in which are often looked over in the primary care setting. I had several patients tell me, "No one has ever asked me about these things before." An occupational therapist can have the role as a consultant in the primary care setting, where their focus can be helping patients redesign and adapt different aspects and factors of their lives in order to better succeed at their daily activities.

Primary care settings would benefit from an enhanced understanding not only what the scope of occupational therapy practice is, but also how occupational therapy can help in practice. Better quality of care, increased reimbursements for services, decreased overall healthcare costs, and a more convenient and holistic method of treating patients are only some of these benefits. Advocating for the role of occupational therapy through academia is another avenue an occupational therapy practitioner can explore. Advocating to related professionals can be done by providing educational seminars at medical schools, mid-level physician schools, nursing programs, and case-manager programs. Adding a lesson to students' curriculum to include what the true scope of occupational therapy is could have a major impact on both the primary care provider profession as well as the occupational therapy profession by significantly improving the 
quality of care given to patients. Once other health professionals understand how certain conditions and diseases can impact a person's ability to participate in their valued activities, the inclusion of occupational therapy could be integrated seamlessly in patient care at the primary level.

\section{Future research/projects}

There are several areas that are related to this project that require additional research and can very well manifest into unique capstone projects. A follow-up with Borrego Health in the future to see if there is an increased number of occupational therapy referrals could be a continuation of this project. Continued advocacy and education around various community clinics about the findings of this capstone project was a goal, however time did not allow for this.

Identifying a primary care facility where an occupational therapist already works, one could gather valuable information that can be shared in hopes of enlightening more facilities into hiring occupational therapists. Information that is central to the goal of having an occupational therapist at every primary care facility would include actual numerical data that shows how for these facilities, cost of healthcare is decreased, quality of care has increased, and there is greater funding given to the clinics.

\section{Conclusion}

This capstone project aimed to explore the role of occupational therapy for adults within a primary care setting by completing functional assessment interviews with patients, reviewing patient charts, and surveying providers and other healthcare staff. The intention of this project was to educate physicians and medical staff about the distinct knowledge and skills held by occupational therapy in hopes of offering a greater understanding of the scope of practice and 
benefit of the addition of occupational therapy to the primary health care team. The end result was that providers as well as other healthcare staff agree that the addition of occupational therapy would benefit their primary care setting. 


\section{References}

American Occupational Therapy Association (AOTA). (2013). [Selected Assessment Tools for OT Reporting of G-Codes and Modifiers], from https://www.aota.org/advocacypolicy/federal-reg-affairs/news/2013/gcodes-chart.aspx.

American Occupational Therapy Association (AOTA). (2014). Occupational therapy practice framework: Domain and process (3rd ed.). American Journal of Occupational Therapy, 68(Suppl. 1), S19-S21. http://dx.doi.org/10.5014/ajot.2014.682006

American Occupational Therapy Association (AOTA). (2018). Primary care. Retrieved from https://www.aota.org/Practice/Manage/primary-care.aspx

Brown, H. (2018). Top 10 clinical problems seen in primary care. GM Peer-Reviewed Medicine for the 50 Patient, (48). Retrieved December 12, 2018, from https://www.gmjournal.co.uk/top-10-clinical-problems-seen-in-primary-care.

Bumphrey, E. E. (1989). Occupational therapy within the primary health care team. British Journal of Occupational Therapy,52(7), 252-255. doi:10.1177/030802268905200703

Centers for Disease Control and Prevention (CDC), U.S. Department of Health \& Human Services. (2018). Retrieved November 17, 2018.

Center for Medicare \& Medicaid Services (CMS), U.S. Department of Health \& Human Services. (2018). Retrieved February 4, 2019.

Cms.gov. (n.d.). Medicare preventive services. Retrieved January 25, 2019, from https://www.cms.gov/Medicare/Prevention/PrevntionGenInfo/medicare-preventiveservices/MPS-QuickReferenceChart-1.html

Dahl-Popolizio, S., Doyle, S., \& Wade, S. (2018). The role of primary health care in achieving global healthcare goals: Highlighting the potential contribution of occupational therapy. World Federation of Occupational Therapists Bulletin,74(1), 8-16. doi:10.1080/14473828.2018.1433770

Dahl-Popolizio, S., Muir, S. L., Davis, K., Wade, S., \& Voysey, R. (2017). Occupational Therapy in Primary Care: Determining Receptiveness of Occupational Therapists and Primary Care Providers. The Open Journal of Occupational Therapy,5(3). doi:10.15453/2168-6408.1372

Dickson, K. L., \& Toto, P. E. (2018). Feasibility of integrating occupational therapy into a care coordination program for aging in place. American Journal of Occupational Therapy, 72, 7204195020. https://doi.org/10.5014/ajot.2018.031419 
Donnelly, C. A., Leclair, L. L., Wener, P. F., Hand, C. L., \& Letts, L. J. (2016). Occupational therapy in primary care: Results from a national survey. Canadian Journal of Occupational Therapy, 83(3), 135-142. doi:10.1177/0008417416637186

Donnelly, C., O'Neill, C., Bauer, M., \& Letts, L. (2017). Canadian occupational performance measure (COPM) in primary pare: A profile of practice. American Journal of Occupational Therapy,71(6). doi:10.5014/ajot.2017.020008

Channing, B. (2016, October 3). City of El Cajon: The California voting rights act and El Cajon's by-district voting measure [PDF]. El Cajon.

Data USA. (2015). El Cajon, CA. Retrieved from https://datausa.io/profile/geo/el-cajon-ca/

Fqhc.org. (n.d.). What is an FQHC? Retrieved January 25, 2019, from https://www.fqhc.org/what-is-an-fqhe/

Gallagher, A. M., Lyons, B., Houston, C., \& Cummins, M. (2016). Exploring the current and potential role for occupational therapists in managing depression in primary care settings: Perspectives of occupational therapists in Ireland. The Irish Journal of Occupational Therapy,44(2), 10-18.

Halle, A. D., Mroz, T. M., Fogelberg, D. J., \& Leland, N. E. (2018). Occupational therapy and primary care: Updates and trends. American Journal of Occupational Therapy,72(3). doi:10.5014/ajot.2018.723001

Health Resources and Services Administration (HRSA). (2018). Health centers and the affordable care act fact sheet. Retrieved from http://bphc.hrsa.gov/about/healthcenterfactsheet.pdf

Healthserviceinc.org. (2018). Patient-centered medical home. Retrieved January 25, 2019, from https://www.healthservicesinc.org/about/pcmh/

Holstein, B. A. (2018). Managing chronic disease in affordable primary care. The Journal for Nurse Practitioners, 14(6). doi: 10.1016/j.nurpra.2018.03.007

Improvingchroniccare.org. (n.d.). Reducing care fragmentation. Retrieved from http://www.improvingchroniccare.org/index.php?p=Care_Coordination\&s=326

Katz, S., MD. (1983). Assessing Self-maintenance: Activities of Daily Living, Mobility, and 
Instrumental Activities of Daily Living. Journal of the American Geriatrics Society,31(12), 721-727. doi:10.1111/j.1532-5415.1983.tb03391

Lamb, A. J., \& Metzler, C. A. (2014). Health policy perspectives - defining the value of occupational therapy: A health policy lens on research and practice. American Journal of Occupational Therapy, 68, 914. http://dx.doi.org/10.5014/ajot.2014.681001

Lawton, M., \& Brody, E. M. (1969). The Gerontologist. Assessment of Older People: Selfmaintaining and Instrumental Activities of Daily Living,9(3), 179-186.

Linzer, M., Bitton, A., Tu, S., Plews-Ogan, M., Horowitz, K. R., \& Schwartz, M. D. (2015). The end of the 15-20-minute primary care visit. Journal of General Internal Medicine,30(11), 1584-1586. doi:10.1007/s11606-015-3341-3

Montenegro, H., Holder, R., Ramagem, C., Urrutia, S., Fabrega, R., Tasca, R., Gomes, M. A. (2011). Combating health care fragmentation through integrated health service delivery networks in the Americas: Lessons learned. Journal of Integrated Care, 19(5), 5-16. doi:10.1108/14769011111176707

Moyers, P. A., \& Metzler, C. A. (2014). Health policy perspectives- interprofessional collaborative practice in care coordination. American Journal of Occupational Therapy, 68, 500-505. http://dx.doi.org/10.5014/ajot.2014.685002

Muir, S., MOT, OTR/L, Farmer, M., OTD, OTR/L, \& Prestwich, B., MD. (2013, February 28). Achieving the goals of healthcare reform: introduction to occupational therapy in primary care. Lecture. Retrieved from https://www.aota.org/media/Corporate/Files/Advocacy/Health-Care Reform/otprimarycare.pdf

Muir, S. (2012). Occupational therapy in primary health care: We should be there. American Journal of Occupational Therapy,66(5), 506-510. doi:10.5014/ajot.2012.665001

Murphy, A. D., Griffith, V. M., Berkeridge, T., Mroz, T. M., \& Jirikowic, T. L. (2017). Primary care for underserved populations: Navigating policy to incorporate occupational therapy into federally qualified health centers. American Journal of Occupational Therapy,71(2). doi:10.5014/ajot.2017.712001

National Committee for Quality Assurance (NCQA). (2016). Standards and guidelines for NCQA patient-centered medical home 2014 [PDF]. Washington, DC: NCQA. https://iss.ncqa.org/RDSat/2014PCMH/adminPP/1. PCMH Recognition 2014_Front Matter 11.21.2016 FINAL.pdf

Nielsen, T. L., Petersen, K. S., Nielsen, C. V., Strom, J., Ehlers, M. M., \& Bjerrum, M. (2016). 
What are the short-term and long-term effects of occupation-focused and occupationbased occupational therapy in the home on older adults' occupational performance? A systematic review. Scandinavian Journal of Occupational Therapy,24(4), 235-248. doi:10.1080/11038128.2016.1245357

Ostbye, T., Yarnall, K. S., Krause, K. M., Pollak, K. J., Gradison, M., \& Michener, J. (2005). Is there time for management of patients with chronic diseases in primary care? The Annals of Family Medicine,3(3), 209-214. doi:10.1370/afm.310

Pizzi, M. A., \& Richards, L. G. (2017). Guest Editorial—Promoting health, well-being, and quality of life in occupational therapy: A commitment to a paradigm shift for the next 100 years. American Journal of Occupational Therapy, 71, 7104170010. https://doi.org/10.5014/ajot.2017.028456

Pyatak, E. A., Carandang, K., \& Davis, S. (2015). Developing a manualized occupational therapy diabetes management intervention: resilient, empowered, active living with diabetes. The Occupational Therapy Journal of Research, 35 (3), 187-194

Rogers, A. T., Bai, G., Lavin, R. A., \& Anderson, G. F. (2016). Higher hospital spending on occupational therapy is associated with lower readmission rates. Medical Care Research and Review, 74(6), 668-686. doi:10.1177/1077558716666981

Sandelowsky, H., Hylander, I., Krakau, I., Modin, S., Ställberg, B., \& Nager, A. (2016). Time pressured deprioritization of COPD in primary care: A qualitative study. Scandinavian Journal of Primary Health Care,34(1), 55-65. doi:10.3109/02813432.2015.1132892

Shirley Ryan AbilityLab. (2019). Rehabilitation Measures Database. Retrieved from https://www.sralab.org/rehabilitation-measures/database

Spar, M. J., Nicosia, F. M., Steinman, M. A., \& Brown, R. T. (2017). Current approaches to measuring functional status among older adults in VA primary care clinics. HHS Public Access, 34(9), 26-31. Retrieved December 13, 2018, from https://www.ncbi.nlm.nih.gov/pmc/articles/PMC5915328/.

Thibeault, R., \& Hebert, M. (1997). A congruent model for health promotion in occupational therapy. Occupational Therapy International,4(4), 271-293. doi:10.1002/oti.60

Tran, H. T., \& Leonard, S. D. (2017). Geriatric assessment for primary care providers. Primary Care: Clinics in Office Practice,44(3), 399-411. doi:10.1016/j.pop.2017.05.001

Waite, A. (2014). Prime models: showcasing occupational therapy's role on primary care teams. OT Practice 19(7), 8-10, 19. http://dx.doi.org/10.7138/otp.2014.197f1 
Walden, J., MD. (2016). An overlooked cause of physician burnout. American Academy of Family Physicians,23(1).

World Health Organization (WHO). (2010.) Framework for action on interprofessional education and collaborative practice. Retrieved from http://www.who.int/hrh/resources/framework_action/en

Yarnall, K. S., Pollak, K. I., Ostbye, T., Krause, K. M., \& Michener, J. L. (2003). Primary care: is there enough time for prevention? American Journal of Public Health,93(4), 635-641. doi:10.2105/ajph.93.4.635 
Appendix A

Occupational Participation Assessment for Primary Care 
Appendix A

1

\begin{tabular}{|c|c|c|c|}
\hline \multicolumn{4}{|c|}{ Occupational Participation Assessment for Primary Care (OPAPC) } \\
\hline Age (yos) & & Home type & House Apt Mabile Homeless \\
\hline $\mathrm{M} / \mathrm{F}$ & & Bathroom & Walk-in Shower $\angle$ Rathtub \\
\hline $\begin{array}{l}\text { ER visits in } \\
\text { past } 1 \text { year }\end{array}$ & & Lives with & 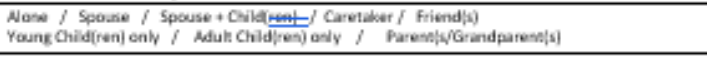 \\
\hline $\begin{array}{c}\text { A Primary } \\
\text { care doctor } \\
\text { visits per year }\end{array}$ & $\begin{array}{l}\text { Is todars visit: } \\
\text { ACUTE or CHRONIC }\end{array}$ & $\begin{array}{c}\text { DME } \\
\text { owned }\end{array}$ & $\begin{array}{l}\text { Pawerchair W/E FWW 4WW Cane Shawer-chair } \\
\text { Tub-bench Grab-tars NONE Other: }\end{array}$ \\
\hline
\end{tabular}

Independent/Assistance or / Dependent

\begin{tabular}{|c|c|c|}
\hline ADLs/IADL5: & Supervision & \\
\hline Getting in/out of bed & & \\
\hline Getting in/out of bath/shower & & \\
\hline Bathing & & \\
\hline Upper body dressing & & \\
\hline Lawer body dressing & & \\
\hline Grooming \& Hygiene & & \\
\hline Getting on/off toilet & & \\
\hline Toilet hygiene & & \\
\hline $\begin{array}{l}\text { Personal device care (hearing aids, contacts, glasses, orthotics, prosthetics, assistive equipment, } \\
\text { glucometers) }\end{array}$ & & \\
\hline Making yourself a meal & & \\
\hline Feeding & & \\
\hline Ability to use a phone & & \\
\hline $\begin{array}{l}\text { Driving or use of community transportation services (A.re you able to get to wherever you want/need at } \\
\text { any time? }\end{array}$ & & \\
\hline Financial management, paying bills on time & & \\
\hline $\begin{array}{l}\text { Health management, medication management } \\
\text { How mony medicatians do you currentily toke? } \\
\text { Do you follow your medication instructions } 100 \% \text { of the time? Yes / No } \\
\text { Are you campliant with schediling and keeping your medical appointments? }\end{array}$ & & \\
\hline Housework, Laundry & & \\
\hline Grocery shopping & & \\
\hline $\begin{array}{l}\text { Getting ready for bed How many hours of sleep do you typically get a night? ___ Do you feel well- } \\
\text { rested? } y / \mathrm{N}\end{array}$ & & \\
\hline
\end{tabular}

For activities that you require assistance for, is assistonce ovoiloble $100 \%$ of the time? Yes / No f(f no, why?)

Do any of the above activities cause pain or aggravate existing pain? Yes / No

If yes, lacotion of poin? ___ If yes, is your poin being managed? Yes / No

Do ony of the above activities cause shortness of breath (SOB)? Yes / No

Over the post few months, hove you noticed ony changes in your sensotion, like numbness or tingling? yes 1 No

If yes, has this affected your ability to participote in pll_of your doily activities? Yes / No

Over the post few months, have you noticed that you were losing strength and/or muscle mass? Yas 1 No

If yes, has this affected your ability to porticipote in pllsof your doily activities? Yes / No

Balance
\begin{tabular}{|l|l|l|}
\hline Over the past week, have you ever felt unsteady or had a loss of balance? How many times? & & \\
\hline Over the last 1-year, have you ever fallen? How many times? & & \\
\hline
\end{tabular}

Over the past ONE MONTH have you: $\quad$ Yes Sometimes Never

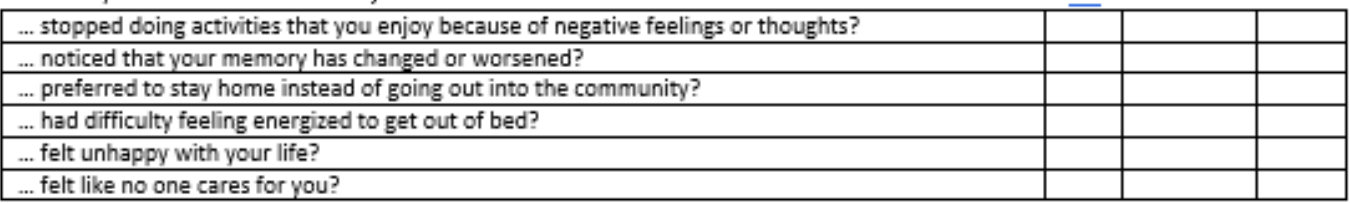

Safety check: If you were home alone and an emergency happened, what would you do?... Appropriate Response Yes / No

THIS PROJECT HAS BEEN REVIEWED BY THE UNIVERSITY OF ST. AUGUSTINE FOR HEALTH SCIENCES INSTITUTIONAL REVIEW BOARD FOR THE PROTECTION OF HUMAN SUBJECTS.

IF YOU HAVE QUESTIONS OR CONCERNS, PLEASE CONTACT THE INSTITUTIONAL IRB CHAIR, DR. ELIZABETH ARDOLINO, EMAIL: EARDOLINO@USA.EDU, PHONE: 737-202-3343. 
Appendix B

Occupational Participation Assessment for Primary Care (SPANISH) 
Appendix B

Occupational Participation Assessment for Primary Care (OPAPC)

\begin{tabular}{|c|c|c|c|}
\hline Edad & & Casa & Casa Apt Móvil Sin Hogar \\
\hline $\mathrm{M} / \mathrm{F}$ & & Baño & Con bañera / Sin bañera \\
\hline $\begin{array}{c}\text { a de } \\
\text { Emergencias }\end{array}$ & & Vive con & 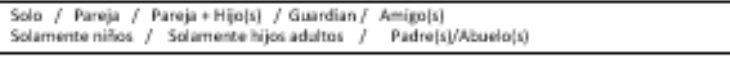 \\
\hline $\begin{array}{l}\text { VVisitas por } \\
\text { aho con su Dr. } \\
\text { primario }\end{array}$ & $\begin{array}{l}\text { La visita de hoy es: } \\
\text { Enfermedad nueva o } \\
\text { cranica }\end{array}$ & $\begin{array}{l}\text { Es dueño de } \\
\text { equipo } \\
\text { medico }\end{array}$ & 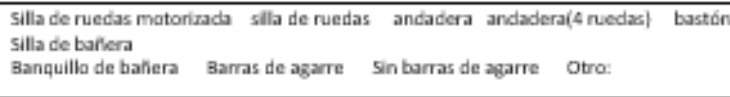 \\
\hline
\end{tabular}

Dependiente Actividades diarias::

Independiente / Asistencia o /

Supervisión

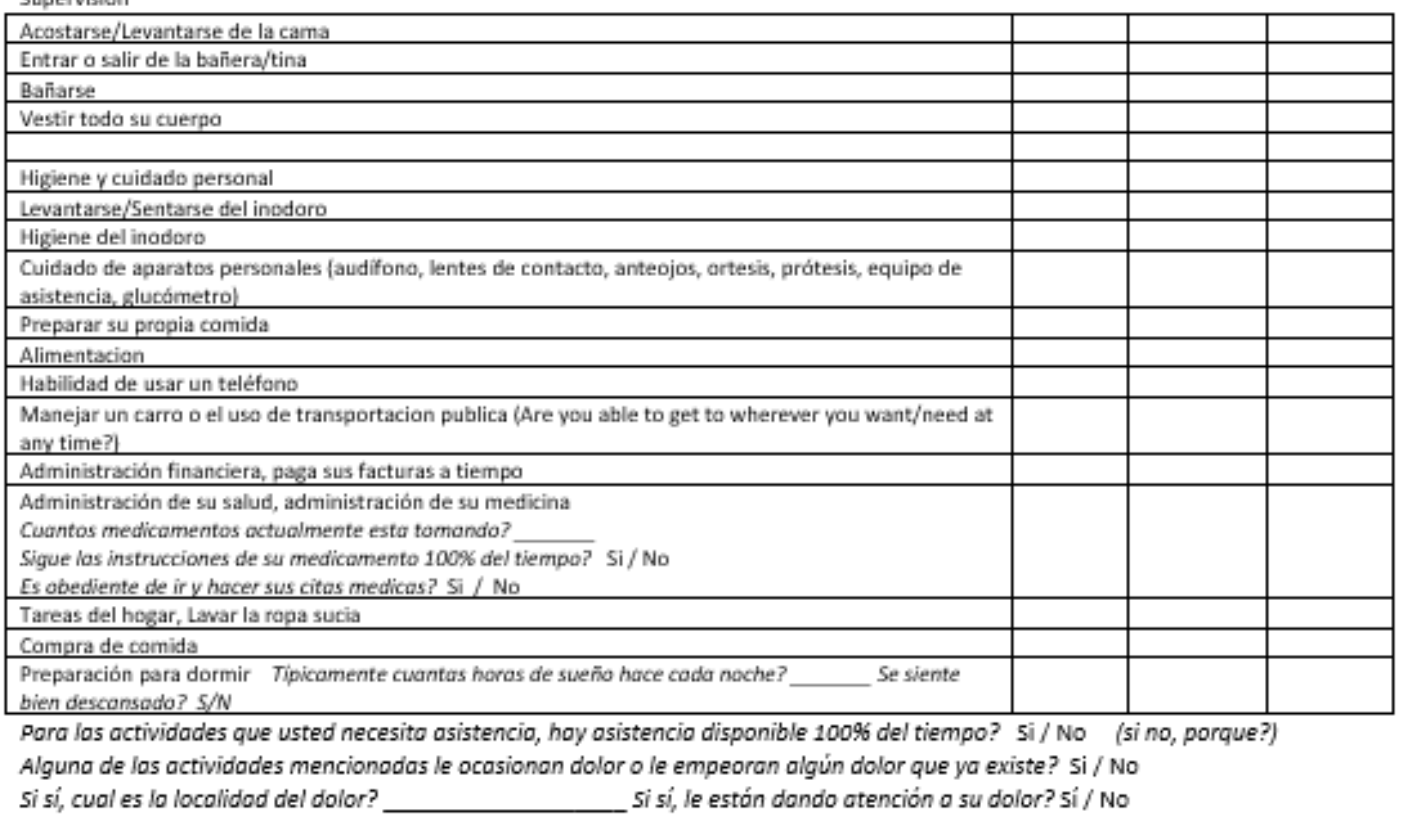

Alguna de los actividades mencionodas le ocasionan la falta de aliento? si / No

Sobre los úitimos cuantos meses, ho notodo algún cambio en su sensación, como entumido o hormigueo? si / No si si,le ho afectodo su habilidad de participor en todas sus actividades diarias? si / No sobre los úitimos cuantos meses, ho notodo haber perdido fuerzas y/o masa muscular? sí / No si si, le ho afectodo su habilidad de participor en todas sus actividades diarias? sí / No

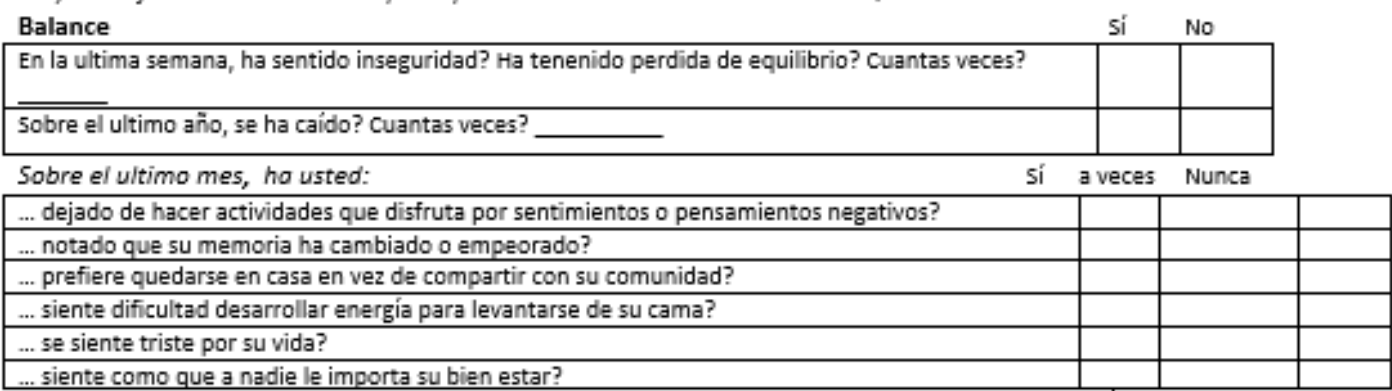

Verificación de Seguridad: Si estuviera en casa a solas y una emergencia ocurre, que hario?... Appropriate Response sí / No

THIS PROJECT HAS BEEN REVIEWED BY THE UNIVERSITY OF ST. AUGUSTINE FOR HEALTH SCIENCES INSTITUTIONAL REVIEW BOARD FOR THE PROTECTION OF HUMAN SUBJECTS.

IF YOU HAVE QUESTIONS OR CONCERNS, PLEASE CONTACT THE INSTITUTIONAL IRB CHAIR, DR. ELIZABETH ARDOLINO, EMAIL: EARDOLNO@USA.EDU, PHONE: 737-202-3343. 
Appendix C

\section{Healthcare Staff Presentation}




\section{Appendix C}
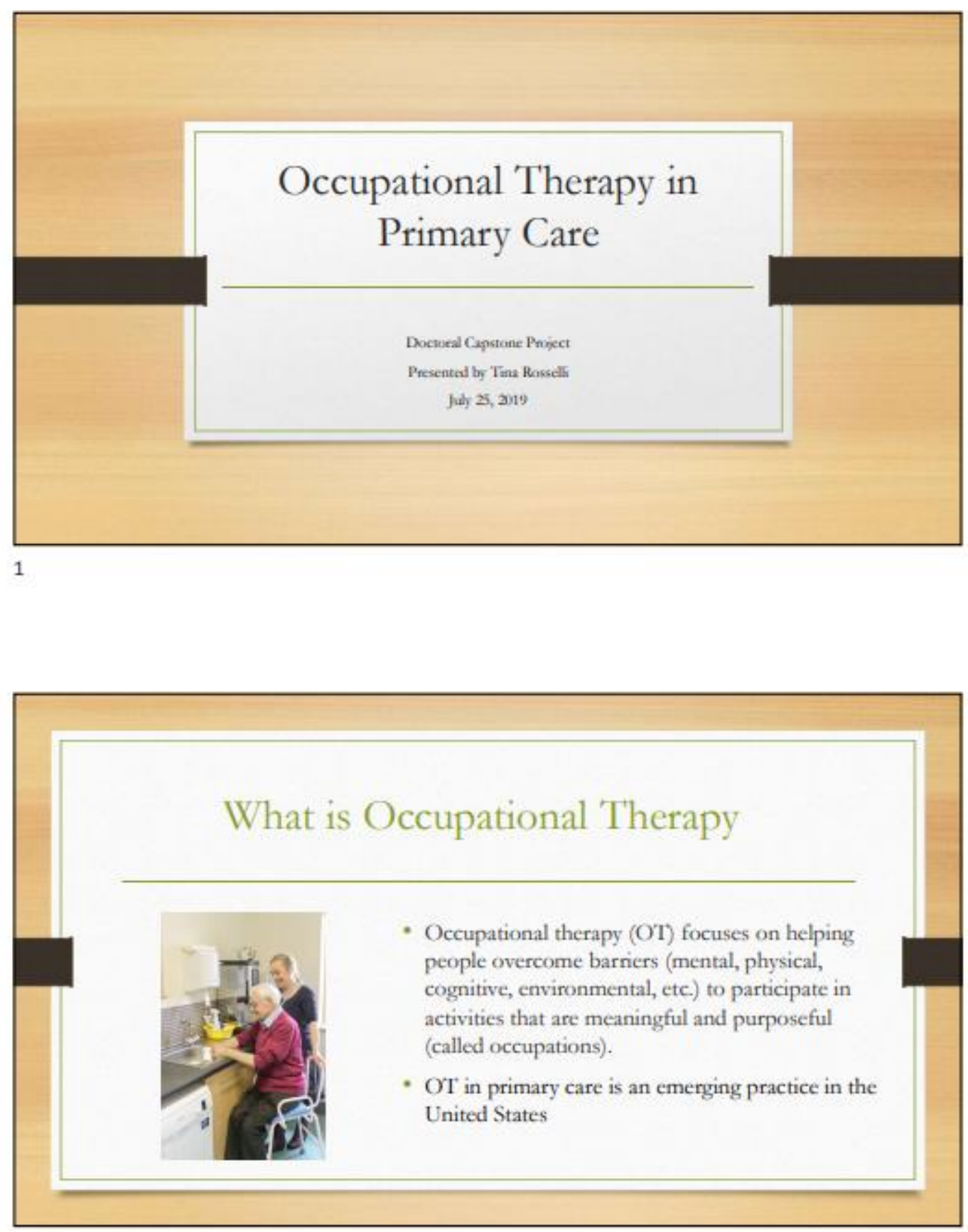


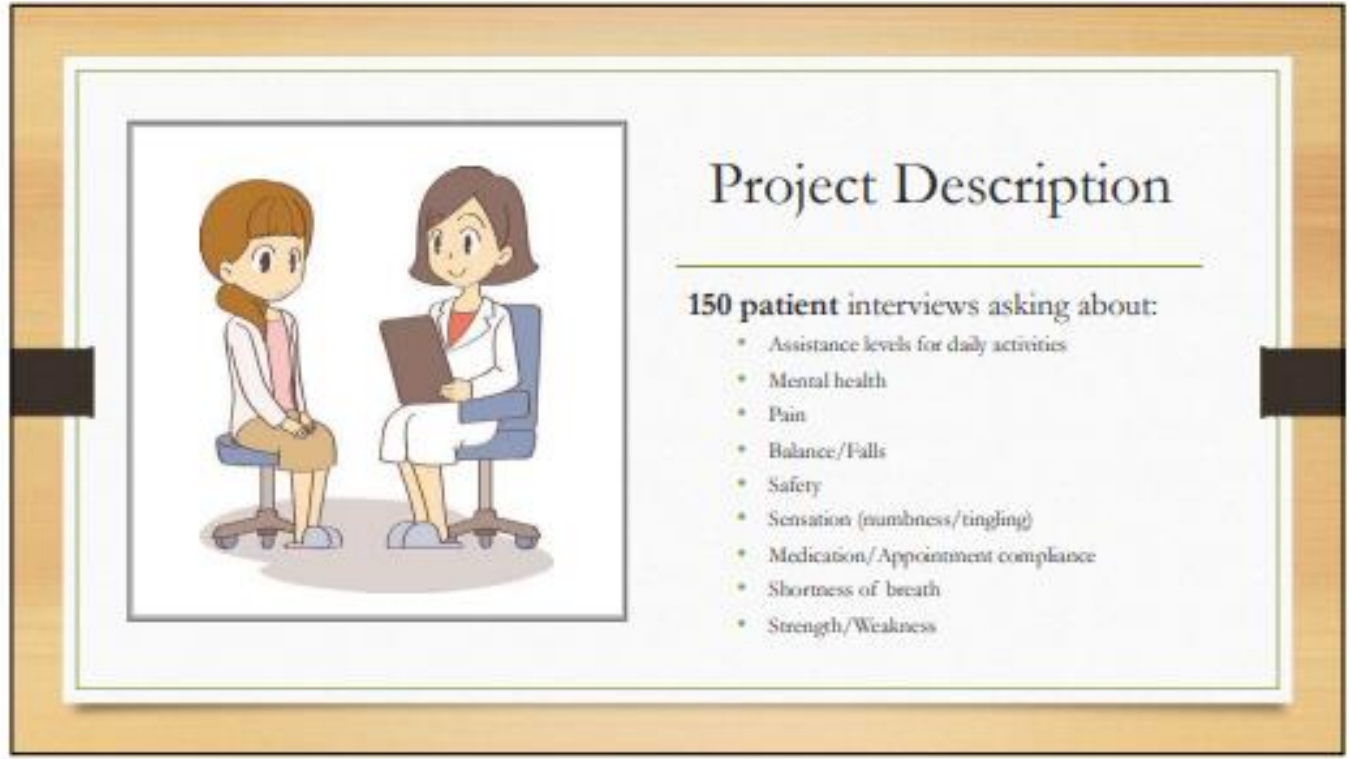

3

\section{Borrego Case Examples}

- Middle-aged adult w/ anxiety. Forgets important items while grocery shopping $\mathrm{d} / \mathrm{t}$ severity of anxiety.

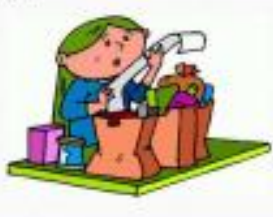

- Older adult w/various falls \& various loss of balance episodes. Patient uses bathtub with no shower chair and relies on wall and shower curtain to get in and out of the shower.

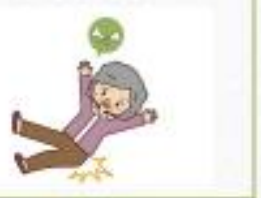




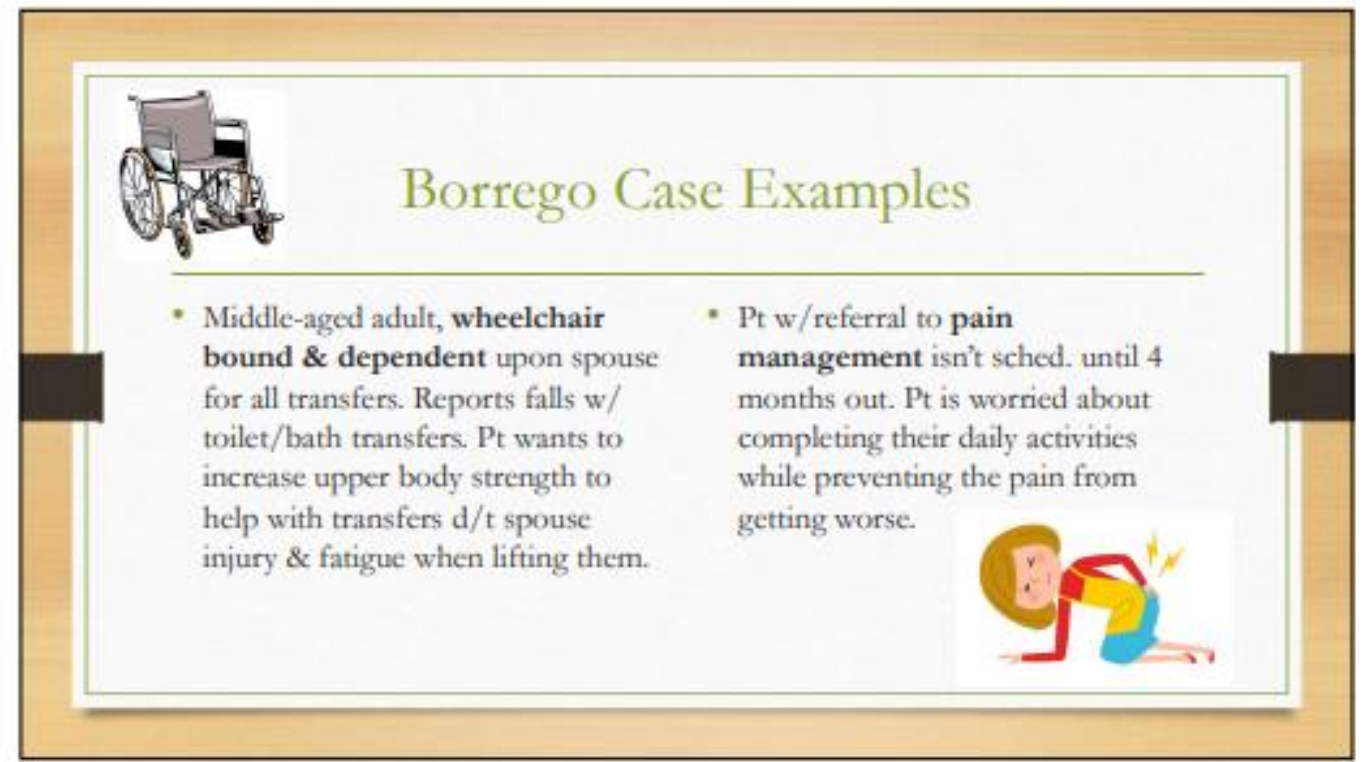

5

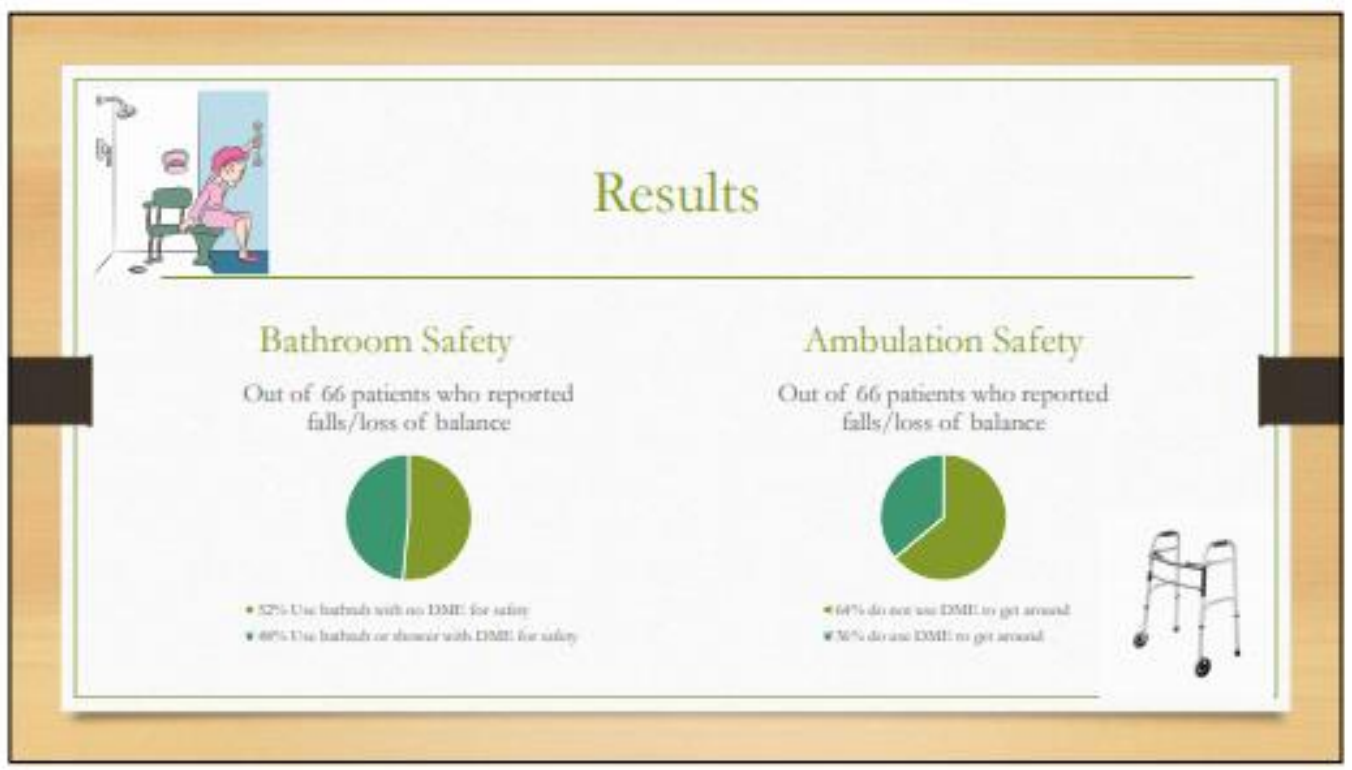

6 


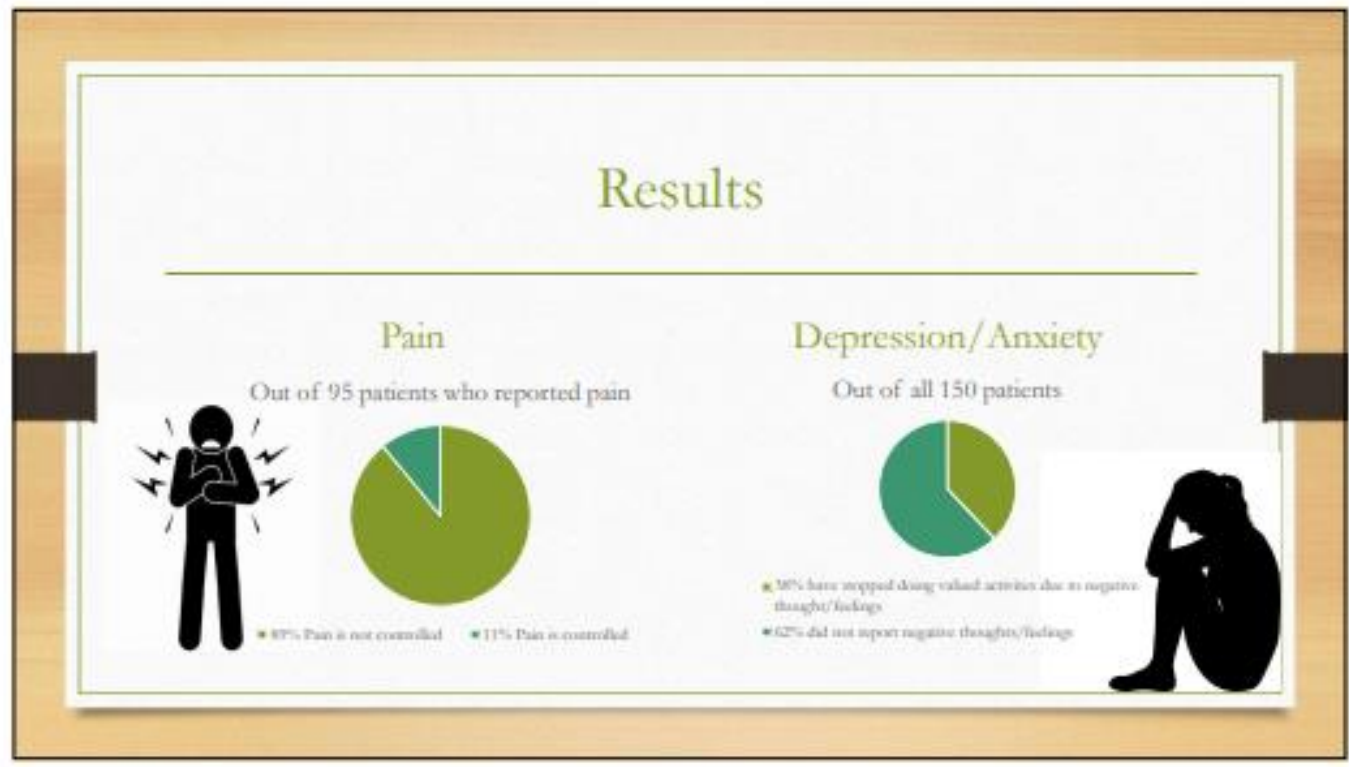

7

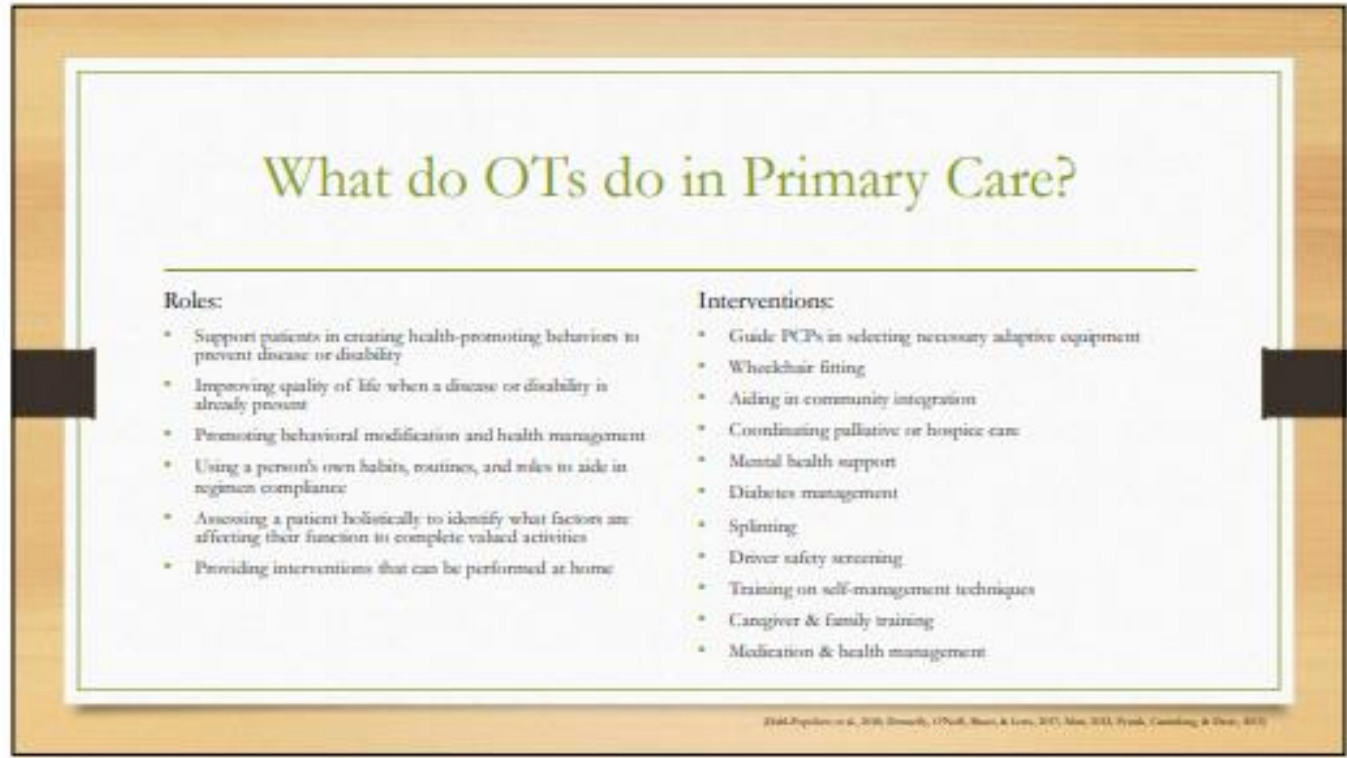




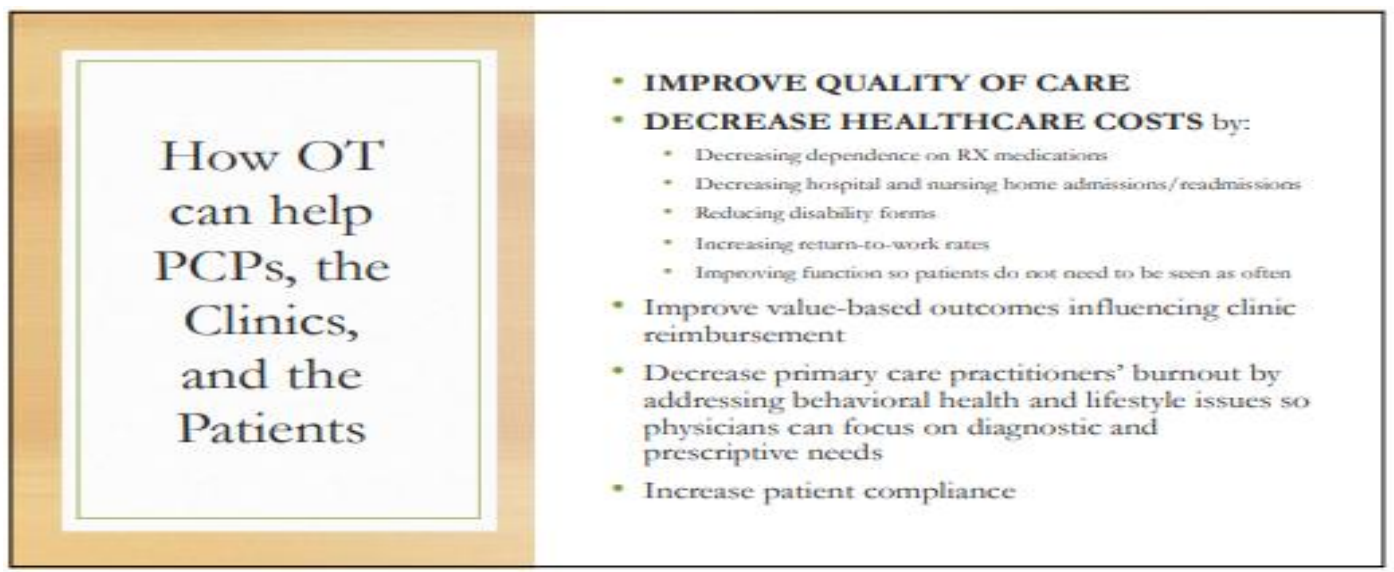

9

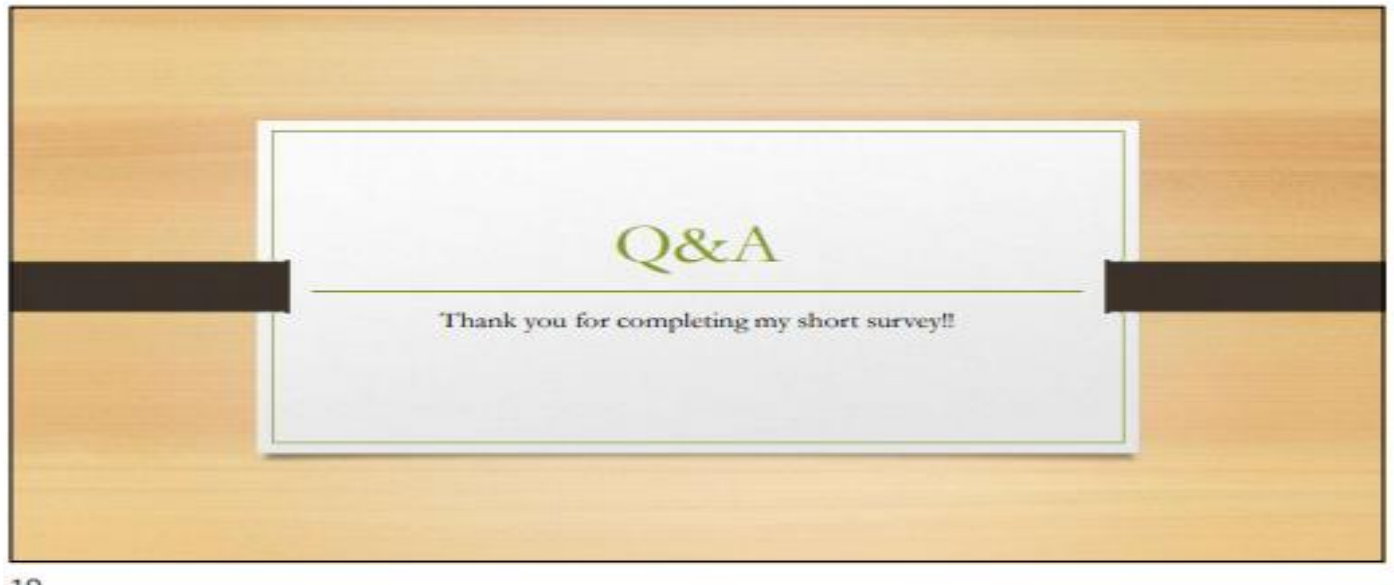

10

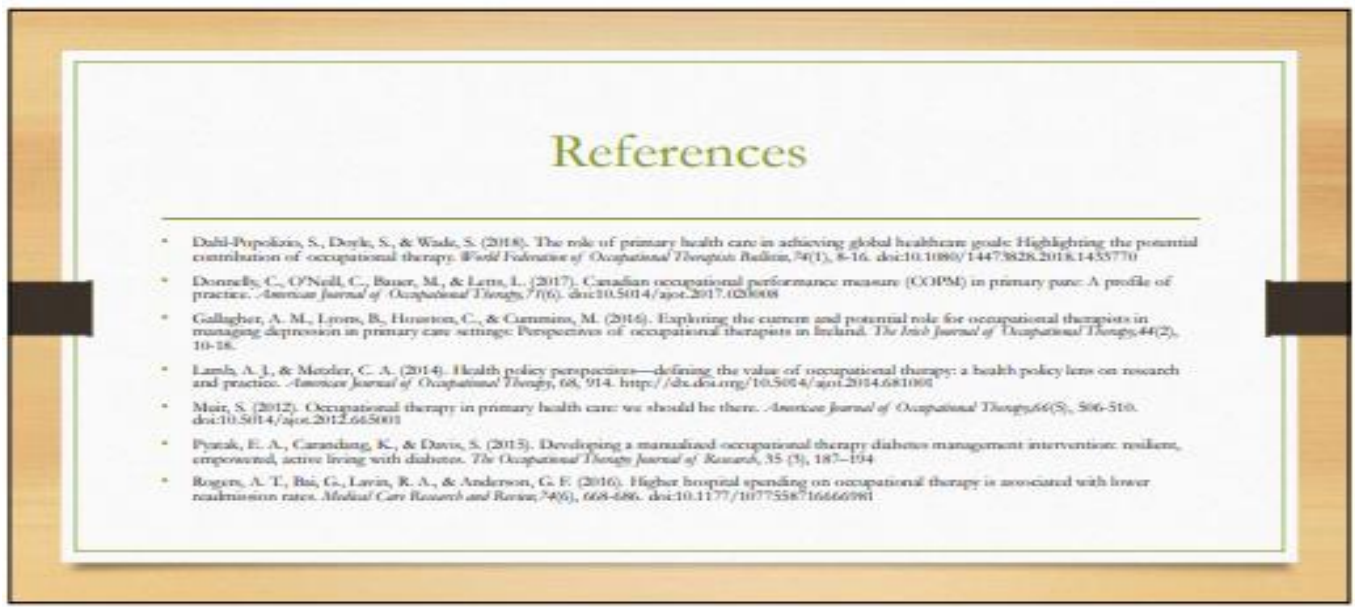

11 
Appendix D

\section{Primary Care Information Packet}


Appendix D

\title{
Exploring the Role of Occupational Therapy in Primary Care
}

\author{
Information Packet
}

A Doctoral Capstone Project completed at Borrego Health

By Tina Rosselli

July 2019 


\section{Table of Contents}

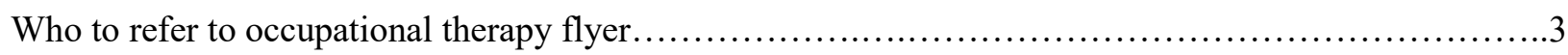

Why is Occupational Therapy important in Healthcare?...........................................................................

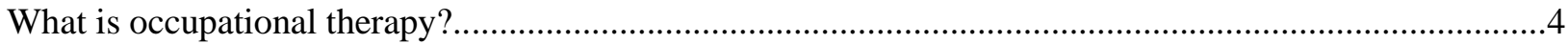

How OTs can help PCPs, the Clinics, and the Patients..........................................

What support do OTs do in Primary Care? .........................................................................................

What can OTs assess?

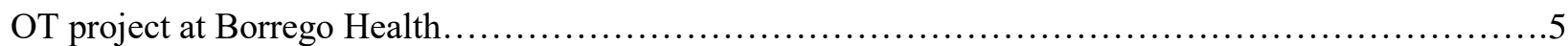

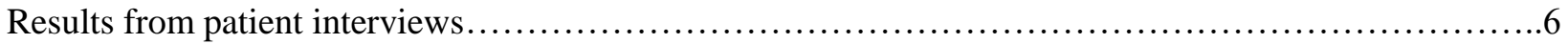

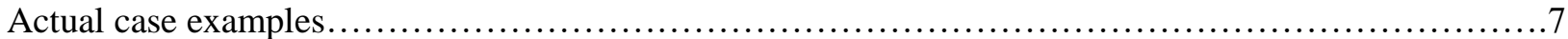

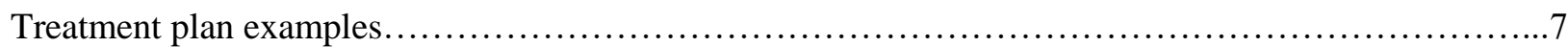




\section{Who to Refer to Occupational Therapy}

\section{ANY DISEASE, DISORDER, CONDITION (PHYSICAL OR MENTAL) \\ THAT IS AFFECTING THEIR FUNCTION}

including, but not limited to:

* Chronic pain \& fatigue

* Chronic condition management (COPD, Diabetes, obesity, neuromuscular disorders, etc.)

* Arthritis

* Cognitive impairment

Repetitive use injuries (carpal tunnel, lateral epicondylitis, etc.)

* DME needs or modifications

* Progressive neurodegenerative disorders (Parkinson's, MS, etc.)

* Mental health

Visual impairments
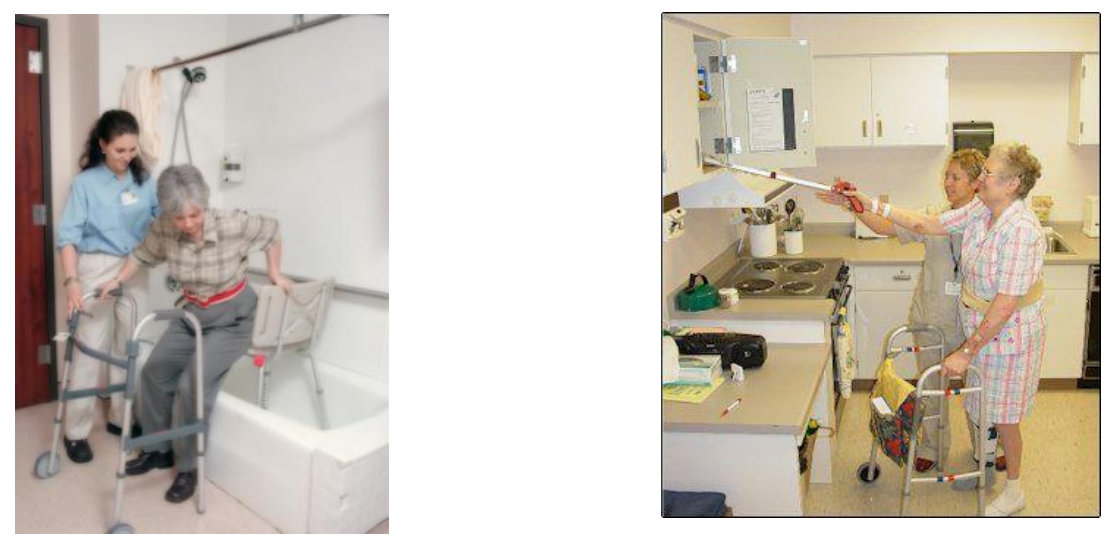


\section{Problems in Healthcare}

- Increased number of patients with multiple chronic conditions

- Older adults aging in place (remaining independent in their homes for longer periods of time) with increased safety risk

- Primary care visit time crunch

- Physician burnout

- Low number of referrals to occupational therapy

- Healthcare professionals' lack of understanding about the scope of occupational therapy practice

- Clinics getting reimbursed based on value of care

- Increase in hospital admissions/readmissions

- Referring patients out of primary care for services that could be rendered in-house, which can lead to fragmented care

\section{What is Occupational Therapy?}

- Occupational therapy (OT) focuses on helping people overcome barriers (mental, physical, cognitive, environmental, etc.) to participate in activities that are meaningful and purposeful (called occupations).

- Occupations can be anything from daily activities (ie. getting out of bed, using a toilet, showering, dressing) to other activities such as managing finances, managing health, driving, caring for a child or pet, leisure activities, sleeping, working, gardening, etc. Absolutely any activity that one considers meaningful and purposeful is an occupation.

- Occupational Therapists (OTs) and Occupational Therapy Assistants (OTA) consider both intrinsic and extrinsic factors in determining interventions, including psychosocial, cultural, physical, and environmental issues, and use occupation as a means to promote health and wellness.

\section{How OT can help PCPs, the Clinics, and the Patients}

- Increase quality of care and value-based outcomes

- Decrease healthcare costs in the following areas:

$\circ$ Decreasing dependence on RX medications

- Decreasing hospital and nursing home admissions/readmissions

- Reducing disability forms

- Increasing return-to-work rates

- Improving function so patients do not need to be seen as often

- Decrease primary care practitioner burnout by addressing behavioral health and lifestyle issues so physicians can focus on diagnostic and prescriptive needs

- Patients are more likely to adhere to your recommendations because OT helps patients identify barriers to medical instruction adherence and finds realistic and sustainable ways for the patient to adhere to instructions

- Providers get a more holistic view of a patient's functional ability as members of the interprofessional primary care team (Lamb \& Metzler, 2014; Rogers, Bai, Lavin, \& Anderson, 2016; Gallagher, Lyons, Houston \& Cummins, 2016) 


\section{What support do OTs do in Primary Care?}

- Support patient in creating health-promoting behaviors to prevent disease or disability

- Improve quality of life when a disease or disability is already present

- Promote behavioral modification and health management

- Use a person's own habits, routines, and roles to aide in regimen compliance

- Assess a patient holistically to identify what factors are affecting their function to complete valued activity

- Provide interventions that can be performed at home

- Guide PCPs in selecting necessary adaptive equipment

- Wheelchair fitting

- Aide in community integration

- Coordinate palliative or hospice care

- Mental health support

- Diabetes management

- Splinting

- Driver safety screening

- Training on self-management techniques (Dahl-Popolizio et al., 2018; Donnelly, O'Neill, Bauer, \& Letts, 2017; Muir, 2012; Pyatak, Carandang, \& Davis, 2015)

\section{What can OTs Assess?}

- Driving education

- Decision making

- Self-care

- Depression

- Strength

- Vestibular

- Sleep

- Processing speed

- Executive function

- Aphasia

- Dexterity

- Life participation

- $\quad$ Stress \& coping

- Personality
- Reaction time
- Sensory
- Fine \& Gross motor
- Behavior
- $\quad$ Self-efficacy
- Swallowing
- Reading comprehension
- Pain
- Cognition
- Balance non-vestibular
- Incontinence
- Negative affect
- Gait
- Word finding

- Visual acuity

- Developmental milestones

- Visual-perceptual skill

- Range of motion

- Upper extremity function

- Spasticity

- Motivation

- Hearing

- Attention \& working memory

- Communication

- Functional mobility

- $\quad$ Reasoning \& problem solving

- Touch

- Dysarthria

\section{OT Project at Borrego Health}

This project, completed at Borrego Health between April 2019 and July 2019, aims to explore the potential role of occupational therapy for adults within a primary care setting by completing functional assessment interviews with patients, reviewing patient charts, learning of any gaps in the current assessment protocol and surveying providers and other healthcare staff after a short presentation.

There was a total of 150 patient interviews completed between the months of April 2019 and June 2019. There were 50 adult patients ( 62 male, 88 female) from each age group [(young: 18-44 yrs.), (middle-aged: 45-64 yrs.), and (older: 65+ yrs.)]. Interview question topics include: type of home (apartment, house, mobile, etc.), how many steps there are to enter the home, whether they have a walk-in shower or a bathtub shower, who they live with and what durable medical equipment they own, how many primary care visits and emergency room visits they have had in a given time, how much assistance is required for their daily activities, whether pain, weakness, sensation deficits, and shortness of breath affect activity, recent balance and fall history, and finally, mental health questions focusing on whether mental health issues have affected their activity engagement. 


\section{Results from Patient Interviews}

- 34 of the 66 participants who reported balance and/or fall issues use a bathtub with no bathroom durable medical equipment (DME) for safety.

- 42 of the 66 participants who reported balance and/or fall issues do not use DME for ambulation safety.

- Out of the 54 participants who require either some or total assistance for a single or multiple ADL/IADL(s), 20 of them reported not always having someone available to help them.

- Regardless of the average amount of sleep hours reported, $51 \%$ of participants reported not feeling wellrested, with $35 \%$ of participants reporting sleeping between $1-5$ hours a night, $57 \%$ reporting sleeping 6-8 hours per night, and $8 \%$ reported sleeping greater than 8 hours per night.

- Of the $63 \%$ of participants who reported having pain on any or multiple body parts/areas during their daily occupations, $89 \%$ reported the pain is not currently being managed.

- Shortness of breath while performing daily occupations affected the middle-aged and older-adult age groups the most, with $32 \%$ of participants affected in each age-group.

- Sensation deficits, such as numbness and/or tingling, was reported to affect $47 \%$ of participants, with $81 \%$ reporting that this deficit affects completing their valued occupations.

- Loss of strength or increase in weakness was reported to affect $58 \%$ of older adults, $38 \%$ of middle-aged adults, and $30 \%$ of young adults. Of those participants who reported loss of strength in all age groups, $94 \%$ reported this deficit affecting their ability to complete their valued daily occupations.

- Of the 50 older adult participants, $64 \%$ reported a loss of balance in the past week and $30 \%$ reported a fall in the past year.

- Mental health: $38 \%$ of all participants have stopped participating in valued occupations due to negative thoughts and/or feelings. Of the older-adult participants, $42 \%$ reported this as true.

- Of all the participants, $40 \%$ reported a change or worsening in their memory, with specifically $58 \%$ of older adults reporting this as true.

- Approximately $37 \%$ of all participants reported feeling unhappy with their lives, while $32 \%$ of all participants felt that they had no one that cares about them.

- All age groups had participants report mental health concerns, however middle-aged participants reported the highest numbers of mental health concerns.

- Out of 150 total participants, 8 reported an inappropriate response to the emergency/safety question, "If you were home alone, and there was an emergency such as your kitchen caught fire, what would you do?"

- Out of all the older-adult participants, $25 \%$ reported they require either some or total assistance for their daily activities, while approximately $8 \%$ of middle-aged participants as well as the young adults reported they require either some or total assistance for daily activities.

- Approximately $18 \%$ of older adults require some or total assistance for functional transfers to include getting in/out of bed, getting in/out shower/tub, and getting on/off the toilet.

- For all age groups, there was a greater difficulty completing lower body dressing compared to upper body dressing, with the more significant difference being that of the older-adults with $12 \%$ reported required some or total assistance for upper body dressing while $28 \%$ reported requiring some or total assistance for lower body dressing.

- Making a meal for oneself was reported as an activity that $30 \%$ of older adults required some or total assistance with.

- All age groups had participants who reported requiring some or total assistance for transportation and transportation arrangements, with $42 \%$ of older adults, $18 \%$ of middle-aged adults, and $16 \%$ of young adults.

- Many older adults (48\%) reported not being able to manage their own finances including bill-payment schedules.

- While $41 \%$ of all participants reported taking between 1-3 medications, $38 \%$ of all participants reported taking over 4 medications. There was a total of $18 \%$ of all participants who reported not being compliant with their medication regimen.

- Other themes noted, but not calculated: Caregiver fatigue and stress 


\section{Actual Case Examples}

1. Middle-aged adult w/ anxiety. Forgets important items while grocery shopping $\mathrm{d} / \mathrm{t}$ severity of anxiety.

2. Older adult w/various falls \& various loss of balance episodes. Patient uses bathtub with no shower chair and relies on wall and shower curtain to get in and out of the shower.

3. Middle-aged adult, wheelchair bound \& dependent upon spouse for all transfers. Reports falls w/ toilet/bath transfers. Pt wants to increase upper body strength to help with transfers $\mathrm{d} / \mathrm{t}$ spouse injury $\&$ fatigue when lifting them.

4. $\mathrm{Pt}$ w/referral to pain management isn't sched. until 4 months out. $\mathrm{Pt}$ is worried about completing their daily activities while preventing the pain from getting worse.

\section{Treatment Plan Examples}

\section{- Anxiety}

- Assess stress-causing agent, environmental assessment, relaxation techniques, coping strategies, systematic desensitization, physical exercise, functional/creative activities

- Dementia

○ (Depending on stage) Memory aids (calendars, journaling, medication reminders, daily routine schedules), maintaining as much independence as possible, caregiver training, transfer training, ADL retraining (verbal, visual, audio, tactile cues), environmental modifications

- Pain

- Treat before pain leads to physical deconditioning, psychological distress, and overutilization of healthcare, self-management, functional goals, proactive pain control (heat/cold), body mechanics \& ergonomics, neuromuscular re-education (over time, persistent pain leads to abnormal movement patterns and posture changes), muscle tension reduction training, communication skills training (managing their pain with less conflict and frustration), proactive problem solving, pacing activities, avoiding flare-ups, home exercise programs

- Cardiopulmonary diseases, disorders, \& post-procedural

○ Early mobilizations, ADL/IADL re-training, activity tolerance, energy conservation techniques, cardiac/sternal precautions, edema/weight management/lymphatic drainage, stress management, therapeutic exercise programs

- Muscular \& Neurological Disorders

○ Motor learning, post-stroke recovery, grip/pinch strength, orthoses, home exercise programs, strength training through occupations, neuro-muscular re-training

- Other

- Manage side-effects of medications, manage fatigue, improve fine motor skills and upper body strength, simplifying tasks (what is the task, why is it needed, best place and time to do task, how can it be made easier), protecting joints with activities, scar massage, splinting, transfer training, caregiver training 


\section{References}

Dahl-Popolizio, S., Doyle, S., \& Wade, S. (2018). The role of primary health care in achieving global healthcare goals: Highlighting the potential contribution of occupational therapy. World Federation of Occupational Therapists Bulletin,74(1), 8-16.

doi:10.1080/14473828.2018.1433770

Donnelly, C., O’Neill, C., Bauer, M., \& Letts, L. (2017). Canadian occupational performance measure (COPM) in primary pare: A profile of practice. American Journal of Occupational Therapy,71(6). doi:10.5014/ajot.2017.020008

Gallagher, A. M., Lyons, B., Houston, C., \& Cummins, M. (2016). Exploring the current and potential role for occupational therapists in managing depression in primary care settings: Perspectives of occupational therapists in Ireland. The Irish Journal of Occupational Therapy,44(2), 10-18.

Lamb, A. J., \& Metzler, C. A. (2014). Health policy perspectives - defining the value of occupational therapy: a health policy lens on research and practice. American Journal of Occupational Therapy, 68, 914. http://dx.doi.org/10.5014/ajot.2014.681001

Muir, S. (2012). Occupational therapy in primary health care: we should be there. American Journal of Occupational Therapy,66(5), 506-510. doi:10.5014/ajot.2012.665001

Pyatak, E. A., Carandang, K., \& Davis, S. (2015). Developing a manualized occupational therapy diabetes management intervention: resilient, empowered, active living with diabetes. The Occupational Therapy Journal of Research, 35 (3), 187-194

Rogers, A. T., Bai, G., Lavin, R. A., \& Anderson, G. F. (2016). Higher hospital spending on occupational therapy is associated with lower readmission rates. Medical Care Research and Review,74(6), 668-686. doi:10.1177/1077558716666981 
Appendix E

\section{Post-Presentation Healthcare Staff Survey}


Appendix E

\section{Exploring the Role of Occupational Therapy (OT) in Primary Care}

Post-Presentation Healthcare Staff Survey
I am a(n): $\square_{\mathrm{DO}} \square_{\mathrm{MD}} \square_{\mathrm{NP}} \square_{\mathrm{PA}} \square_{\mathrm{MA}} \square_{\mathrm{RN}} \square_{\mathrm{DC}} \square_{\text {ther }}$

If you are a provider (DO, MD, NP, PA, DC), please answer the following:

1. Do you agree that you understand the potential role of occupational therapy in primary care? Yes Samewhat

2. Do you feel that you have enough time to address all patient concerns during a regular office visit? Always sometimes Never

3. Can you envision patients in this clinic that would benefit from the skill set of an occupational therapist? Yes Passibly

4. Would you be open to working with an occupational therapist as a member of your interprofessional primary care team?

res

Passibly

Na

If you are any other healthcare staff, please answer the following:

1. Do you agree that you understand the potential role of occupational therapy in primary care? Yes Samewhat

No

2. Can you envision patients in this clinic that would benefit from the skill set of an occupational therapist? Yes Passibly

Na

Comments:

Thank you so much for your time!

This infarmation is intended to inform a capstone project explaring the potential role of ocapational therapy in the family clinic setting. As an or Doctoral student, 1 am pre-licensed and therefore cannat offer any actice based off any given information. Information collected may be shared for educational purpases and/or published, however, no identifiable information will be shared. 
Appendix F

Current Assessment Protocol Documents 
Appendix F

State of Canomia - Heath and Human Services Agency

Deporment of Hearn Care Sarvises

\section{Staying Healthy Assessment}

Adult

\begin{tabular}{|c|c|c|c|c|c|c|}
\hline \multicolumn{2}{|c|}{ Patient's Name (first \& last) } & Date of Birth & & & & Today's Date \\
\hline \multicolumn{2}{|r|}{ Person Completing Form (if patient needs help) } & \multicolumn{4}{|c|}{$\begin{array}{l}\text { Family Member } \square \text { Friend } \\
\text { Other (Specify) }\end{array}$} & $\begin{array}{l}\text { Need help with form? } \\
\quad \square \text { Yes } \square \text { No }\end{array}$ \\
\hline \multirow{2}{*}{\multicolumn{6}{|c|}{$\begin{array}{l}\text { Please answer all the questions on this form as best you can. Circle "Skip" if you do not know an } \\
\text { answer or do not wish to answer. Be sure to talk to the doctor if you have questions about } \\
\text { anything on this form. Your answers will be protected as part of your medical record. }\end{array}$}} & $\begin{array}{c}\text { Need Interpreter? } \\
\square \text { Yes } \square \text { No }\end{array}$ \\
\hline & & & & & & \multirow{2}{*}{$\begin{array}{l}\text { Clinie Use Onily: } \\
\text { Nutrition }\end{array}$} \\
\hline 1 & \multicolumn{2}{|c|}{$\begin{array}{l}\text { Do you drink or eat } 3 \text { servings of calcium-rich foods daily, } \\
\text { such as milk, cheese, yogurt, soy milk, or tofu? }\end{array}$} & Yes & No & Skip & \\
\hline 2 & \multicolumn{2}{|c|}{ Do you eat fruits and vegetables every day? } & Yes & No & Skip & \\
\hline 3 & \multicolumn{2}{|c|}{$\begin{array}{l}\text { Do you limit the amount of fried food or fast food that you } \\
\text { eat? }\end{array}$} & Yes & No & Skip & \\
\hline 4 & \multicolumn{2}{|c|}{ Are you easily able to get enough healthy food? } & Yes & No & Skip & \\
\hline 5 & \multicolumn{2}{|c|}{$\begin{array}{l}\text { Do you drink a soda, juice drink, sports or energy drink most } \\
\text { days of the week? }\end{array}$} & No & Yes & Skip & \\
\hline 6 & \multicolumn{2}{|c|}{ Do you often eat too much or too little food? } & No & Yes & Skip & \\
\hline 7 & \multicolumn{2}{|l|}{ Are you concerned about your weight? } & No & Yes & Skip & \\
\hline 8 & \multicolumn{2}{|c|}{$\begin{array}{l}\text { Do you exercise or spend time doing activities, such as } \\
\text { walking, gardening, swimming for } 1 / 2 \text { hour a day? }\end{array}$} & Yes & No & Skip & Physical Activity \\
\hline 9 & \multicolumn{2}{|l|}{ Do you feel safe where you live? } & Yes & No & Skip & \multirow[t]{5}{*}{ Satety } \\
\hline 10 & \multicolumn{2}{|l|}{ Have you had any car accidents lately? } & No & Yes & Skip & \\
\hline 11 & \multicolumn{2}{|c|}{$\begin{array}{l}\text { Have you been hit, slapped, kicked, or physically hurt by } \\
\text { someone in the last year? }\end{array}$} & No & Yes & Skip & \\
\hline 12 & \multicolumn{2}{|c|}{$\begin{array}{l}\text { Do you always wear a seat belt when driving or riding in a } \\
\text { car? }\end{array}$} & Yes & No & Skip & \\
\hline 13 & \multicolumn{2}{|c|}{ Do you keep a gun in your house or place where you live? } & No & Yes & Skip & \\
\hline 14 & \multicolumn{2}{|l|}{ Do you brush and floss your teeth daily? } & Yes & No & Skip & Dental Health \\
\hline 15 & Do you often feel sad, hopeless, angry & , or worried? & No & Yes & Skip & Meatal Health \\
\hline 16 & Do you often have trouble sleeping? & & No & Yes & Skip & \\
\hline 17 & Do you smoke or chew tobacco? & & No & Yes & Skip & $\begin{array}{l}\text { Alcohol, Tobacco, } \\
\text { Drug Use }\end{array}$ \\
\hline 18 & $\begin{array}{l}\text { Do friends or family members smoke } \\
\text { where you live? }\end{array}$ & in your house or place & No & Yes & Skip & \\
\hline
\end{tabular}




\begin{tabular}{|c|c|c|c|c|c|}
\hline 19 & $\begin{array}{l}\text { In the past year, have you had: } \\
\square \text { (men) } 5 \text { or more alcohol drinks in one day? } \\
\square \text { (women) } 4 \text { or more alcohol drinks in one day? }\end{array}$ & No & Yes & Skip & \multirow{8}{*}{ Sexual Issues } \\
\hline 20 & $\begin{array}{l}\text { Do you use any drugs or medicines to help you sleep, relax, } \\
\text { calm down, feel better, or lose weight? }\end{array}$ & No & Yes & Skip & \\
\hline 21 & Do you think you or your partner could be pregnant? & No & Yes & Skip & \\
\hline 22 & $\begin{array}{l}\text { Do you think you or your partner could have a sexually } \\
\text { transmitted infection (STI), such as Chlamydia, Gonorrhea, } \\
\text { genital warts, etc.? }\end{array}$ & No & Yes & Skip & \\
\hline 23 & $\begin{array}{l}\text { Have you or your partner(s) had sex without using birth } \\
\text { control in the past year? }\end{array}$ & No & Yes & Skip & \\
\hline 24 & $\begin{array}{l}\text { Have you or your partner(s) had sex with other people in the } \\
\text { past year? }\end{array}$ & No & Yes & Skip & \\
\hline 25 & $\begin{array}{l}\text { Have you or your partner(s) had sex without a condom in the } \\
\text { past year? }\end{array}$ & No & Yes & Skip & \\
\hline 26 & Have you ever been forced or pressured to have sex? & No & Yes & Skip & \\
\hline 27 & Do you have other questions or concerns about your health? & No & Yes & Skip & Other Questions \\
\hline
\end{tabular}

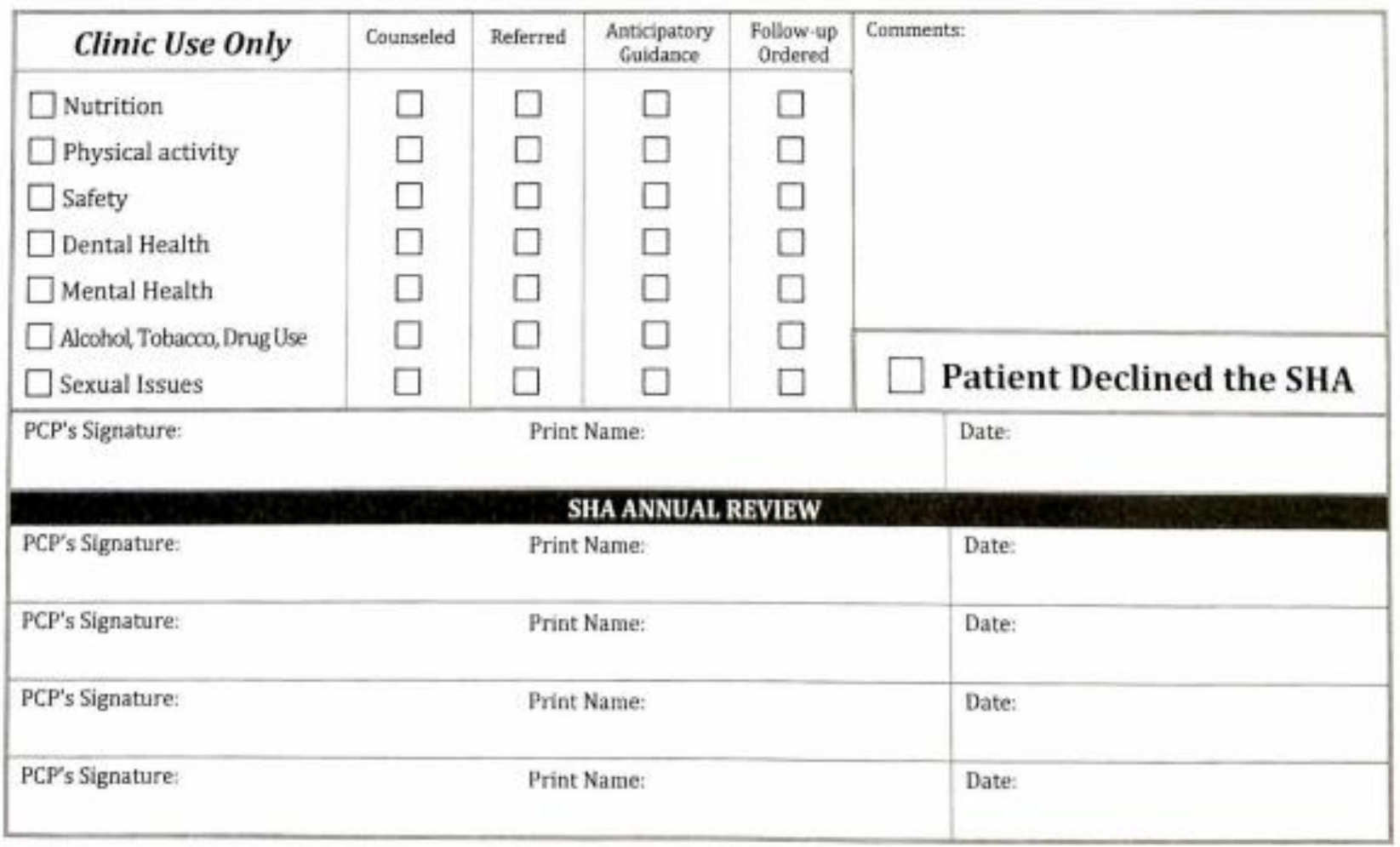




\section{ADULT MEDICAL HISTORY (18 and up)}

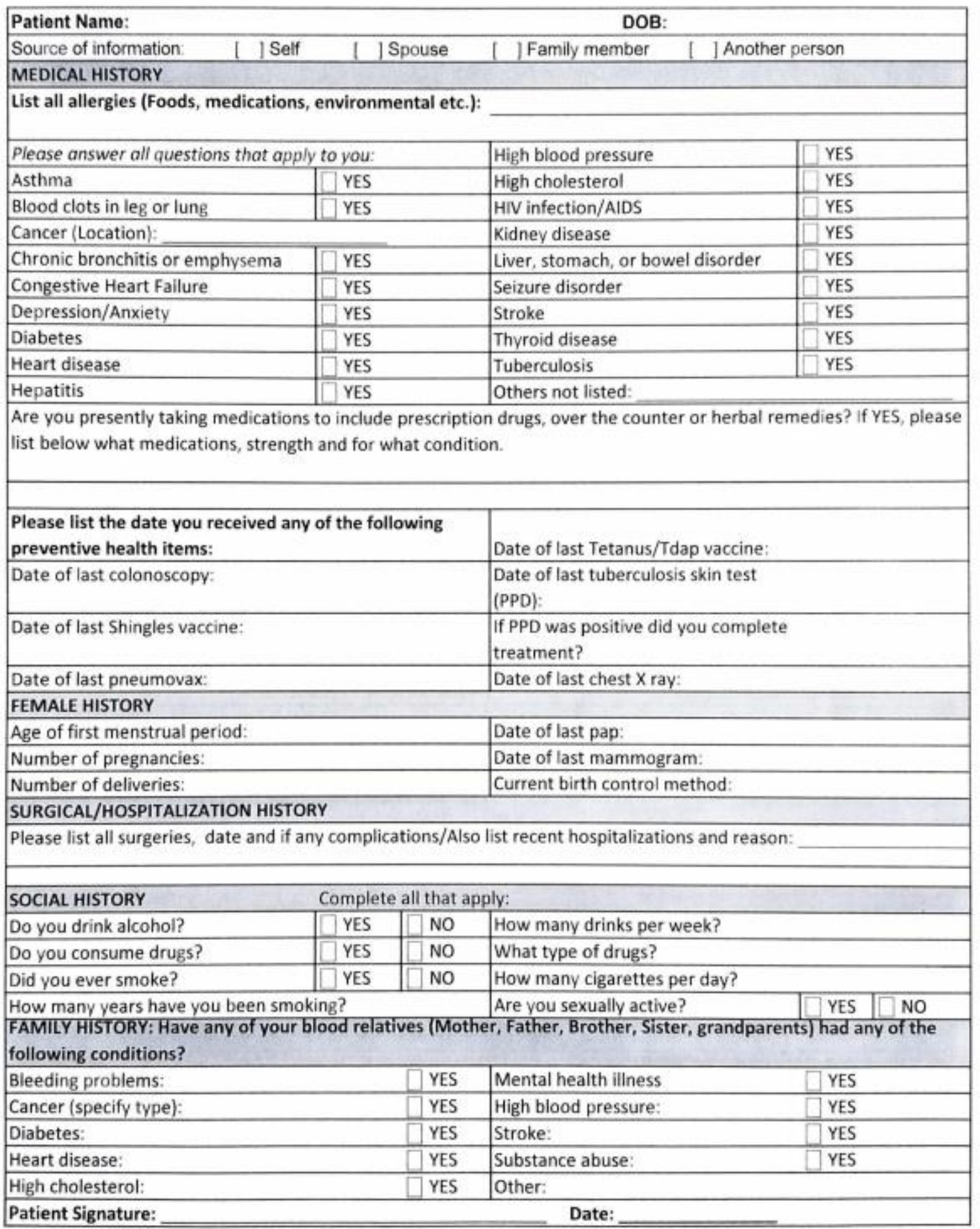




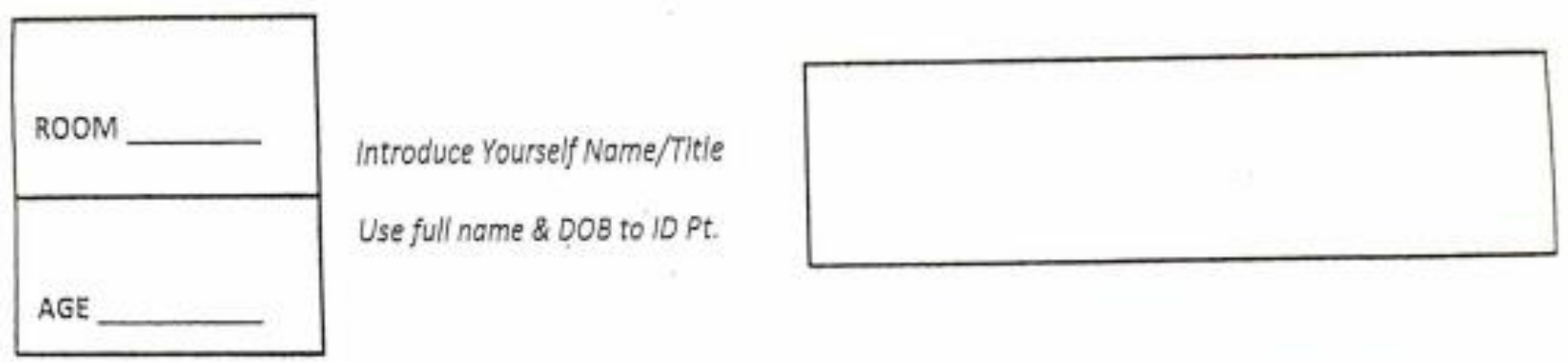

CHIEF COMPLAINT:

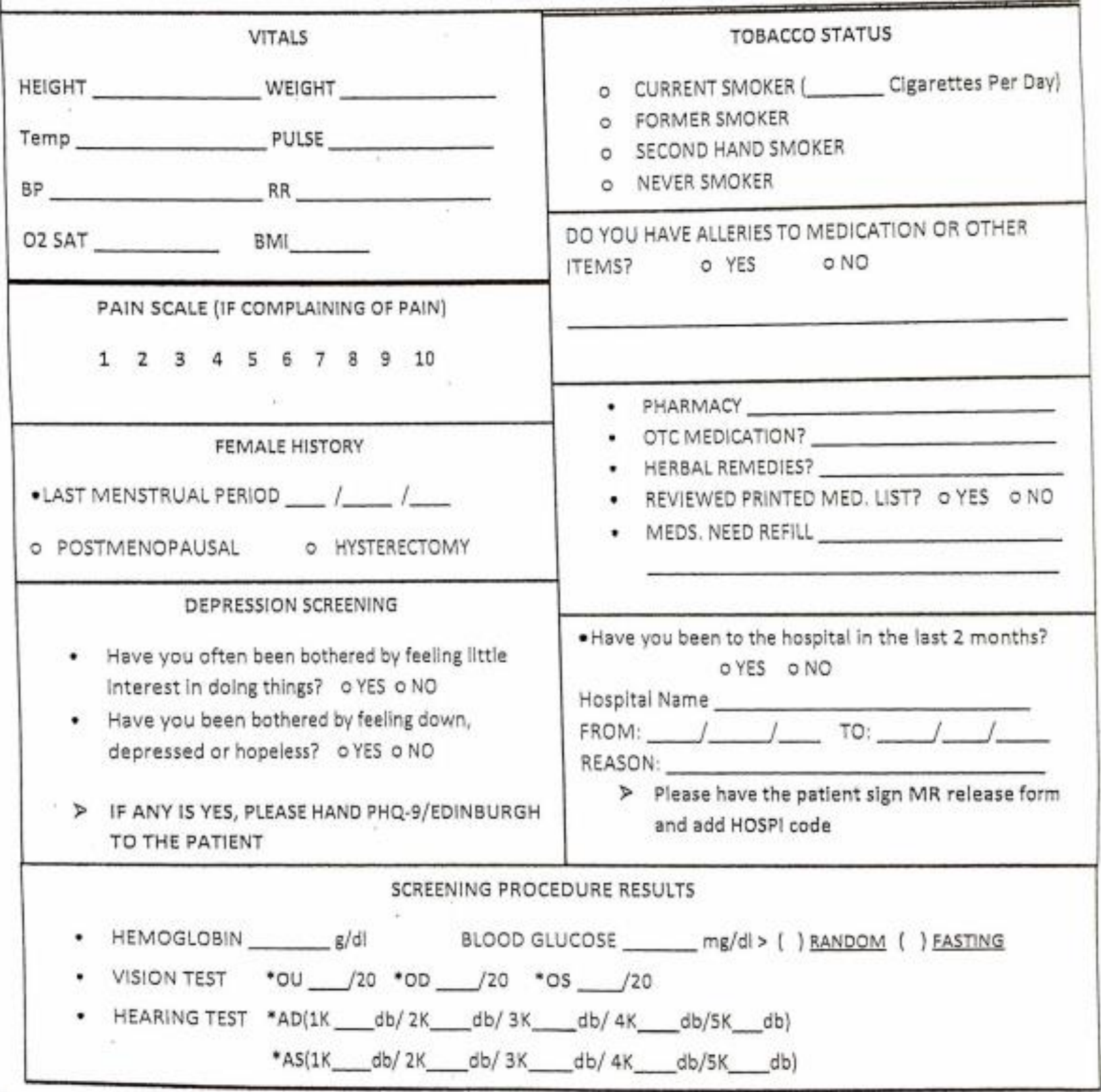




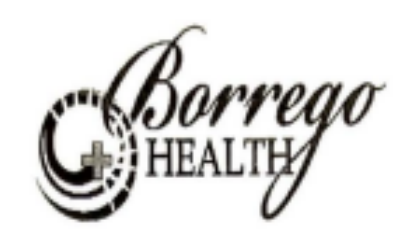

\section{Tuberculosis Risk Assessment Screening Questionnaire}

Today's Date:

Name:

Date of Birth:

*If your child has the appointment today, please fill out the form as it pertains to the child.

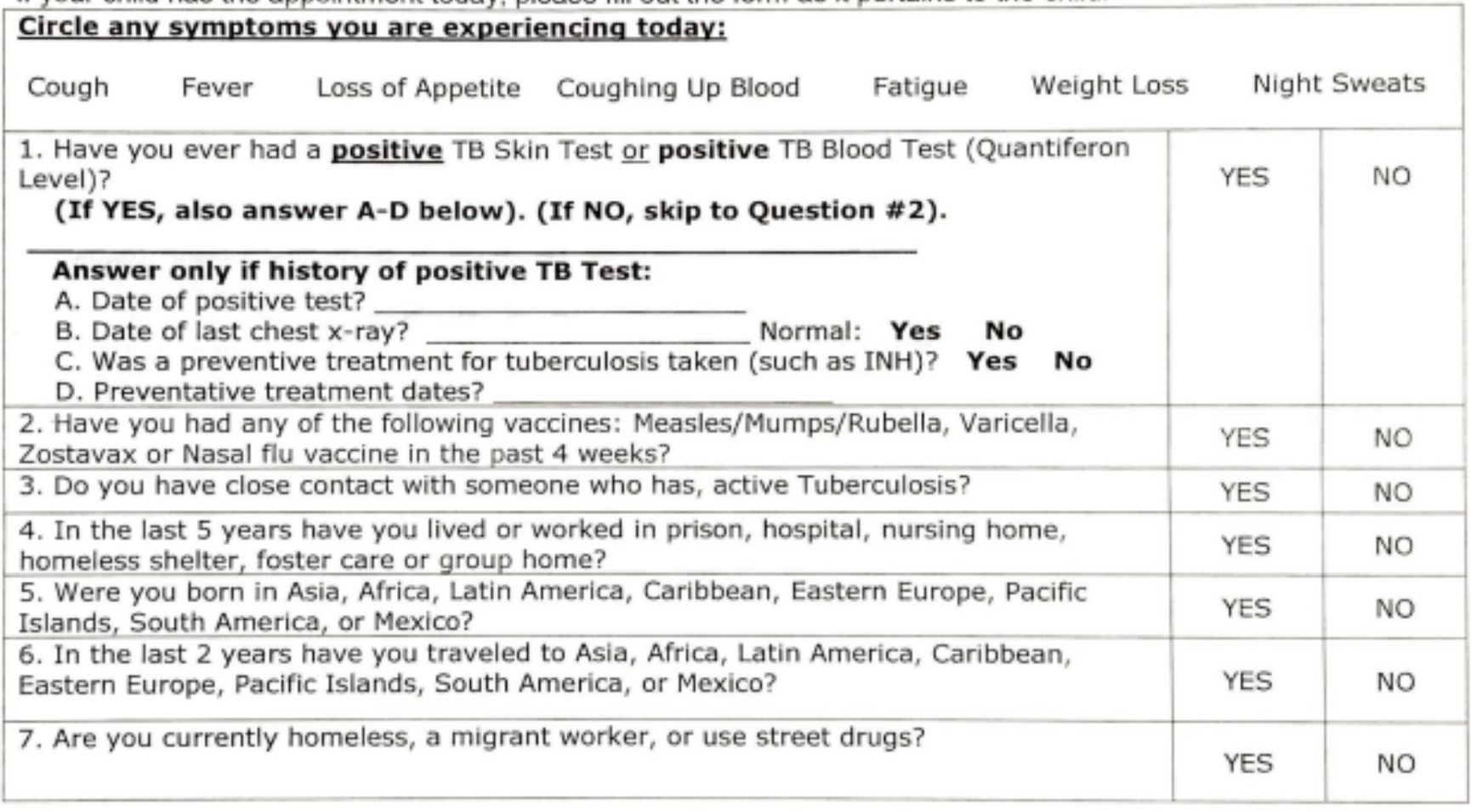

I have received information about the TB skin test and have had the opportunity to ask any questions which were answered to my satisfaction. I agree to return in 48-72 hours to have my TB test read. I understand the risks and benefits of the TB skin test and request the test be administered to me. I understand that if I am symptomatic for TB, or the TB skin test is positive, I will need to follow up with my Primary Care Physician and further treatment may be necessary.

Form Completed By (Signature):

Date:

\section{Print Name:}

Relationship to Patient: (Self), (Parent), (Guardian), Other): 


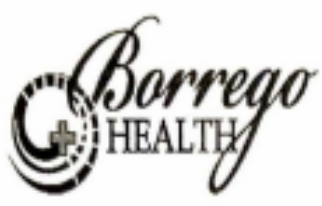

PATIENT IDENTIFICATION LABEL

$\mathrm{PHQ} 2+1$

Pre Screen Questionnaire for Depression

1. Over the past two weeks, have you often been bothered by feeling little interest or pleasure in doing things?

YES__ NO___

2. Over the past two weeks, have you been bothered by feeling down, depressed, or hopeless?

YES__ NO___

+1. Have you been referred to a Mental Health/Behavioral Health Provider in the last 30 days?

YES

NO

FOR STAFF USE:

If any of above questions is answered YES, ask the following question:

Are you currently being seen by a Mental Health/Behavioral Health Provider

YES

NO

If above question is answered NO, administer the PHQ-9 Depression Screen.

If above question is answered YES, ask only Question \#9 of PHQ9:

"In the last two weeks how often have you had thoughts that you would be better off dead, or hurting yourself?"

Not at all__ Several days___ More than half of the days__ Nearly every day

If above Question (\#9 of PHQ9) is answered 1-3, a Risk Assessment will be completed by RN, LVN or a Provider during visit.

\section{What Follow up action was taken?}

_ Patient Refused PHQ-2

_ Patient seen by PCP last 2 weeks

_ Patient Refused PHQ-9

_ Patient in treatment Borrego Health/Elsewhere
- Patient given the PHQ-9

_ Patient referred to BH Provider

_ Patient declined referral to BH

_Referral pending with Behavioral Health

Other: 


\section{PATIENT HEALTH QUESTIONNAIRE-9 (PHQ-9)}

Over the last 2 weeks, how often have you been bothered by any of the following problems? (Use " $\checkmark$ to indicate your answer)

Not at all $\begin{gathered}\text { Several } \\ \text { days }\end{gathered} \quad \begin{gathered}\text { More } \\ \text { than half } \\ \text { the days }\end{gathered} \quad \begin{gathered}\text { Nearly } \\ \text { every } \\ \text { day }\end{gathered}$

1. Little interest or pleasure in doing things

0

$1+2 \quad 3$

2. Feeling down, depressed, or hopeless $\quad 0 \quad 1 \quad 3$

\begin{tabular}{|c|c|c|c|c|}
\hline 3. Trouble falling or staying asleep, or sleeping too much & 0 & 1 & 2 & 3 \\
\hline 4. Feeling tired or having little energy & 0 & 1 & 2 & 3 \\
\hline 5. Poor appetite or overeating & 0 & 1 & 2 & 3 \\
\hline $\begin{array}{l}\text { 6. Feeling bad about yourself }- \text { or that you are a fallure or } \\
\text { have let yourself or your family down }\end{array}$ & 0 & 1 & 2 & 3 \\
\hline $\begin{array}{l}\text { 7. Trouble concentrating on things, such as reading the } \\
\text { newspaper or watching television }\end{array}$ & 0 & 1 & 2 & 3 \\
\hline $\begin{array}{l}\text { 8. Moving or speaking so slowly that other people could have } \\
\text { noticed? Or the opposite - being so fidgety or restless } \\
\text { that you have been moving around a lot more than usual }\end{array}$ & 0 & 1 & 2 & 3 \\
\hline $\begin{array}{l}\text { 9. Thoughts that you would be better off dead or of hurting } \\
\text { yourself in some way }\end{array}$ & 0 & 1 & 2 & 3 \\
\hline
\end{tabular}

FOR OFFCE COOING $+$ $=$ Total Seore:

If you checked off any problems, how difficult have these problems made it for you to do your work, take care of things at home, or get along with other people?

\begin{tabular}{|c|c|c|c|}
\hline $\begin{array}{c}\text { Not difficult } \\
\text { at all } \\
\square\end{array}$ & $\begin{array}{c}\text { Somewhat } \\
\text { difficult } \\
\square\end{array}$ & $\begin{array}{c}\text { Very } \\
\text { difficult } \\
\square\end{array}$ & $\begin{array}{c}\text { Extremely } \\
\text { difficult } \\
\square\end{array}$ \\
\hline
\end{tabular}

Developed by Drs. Robert L. Spitzer, Janet B.W. Willans, Kurt Kroenke and colleagues, with an educational grant from Pfizer Inc. No permission required to reproduce, translate, display or distribute. 
Generalized Anxiety Disorder 7-item (GAD-7) scale

\begin{tabular}{|c|c|c|c|c|}
\hline $\begin{array}{l}\text { Over the last } 2 \text { weeks, how often have you been } \\
\text { bothered by the following problems? }\end{array}$ & $\begin{array}{l}\text { Not at } \\
\text { all sure }\end{array}$ & $\begin{array}{l}\text { Several } \\
\text { days }\end{array}$ & $\begin{array}{l}\text { Over half } \\
\text { the days }\end{array}$ & $\begin{array}{l}\text { Nearly } \\
\text { every day }\end{array}$ \\
\hline 1. Feeling nervous, anxious, or on edge & 0 & 1 & 2 & 3 \\
\hline 2. Not being able to stop or control worrying & 0 & 1 & 2 & 3 \\
\hline 3. Worrying too much about different things & 0 & 1 & 2 & 3 \\
\hline 4. Trouble relaxing & 0 & 1 & 2 & 3 \\
\hline 5. Being so restless that it's hard to sit still & 0 & 1 & 2 & 3 \\
\hline 6. Becoming easily annoyed or irritable & 0 & 1 & 2 & 3 \\
\hline $\begin{array}{l}\text { 7. Feeling afraid as if something awful might } \\
\text { happen }\end{array}$ & 0 & 1 & 2 & 3 \\
\hline Add the score for each column & + & + & + & \\
\hline Total Score (add your column scores) = & & & & \\
\hline
\end{tabular}

If you checked off any problems, how difficult have these made it for you to do your work, take care of things at home, or get along with other people?

Not difficult at all

Somewhat difficult

Very difficult

Extremely difficult

Source: Spitzer RL, Kroeake K, Williams JBW, Lowe B. A brief measure for assessing generalized anxiety
disorder. Arch Inem Med. 2006;166:1092-1097. 